\title{
SOBRE LAS PRECIPITACIONES DE OCTUBRE DE 2012 EN EL PIRINEO ARAGONÉS, SU RESPUESTA HIDROLÓGICA Y LA GESTIÓN DE RIESGOS
}

\author{
Vanesa Acín Naverac' ${ }^{1}$, Daniel Ballarín Ferrer ${ }^{2}$, Pedro Brufao Curiel ${ }^{3}$, \\ Sergio Domenech Zueco ${ }^{4}$, Francisco Espejo Gil ${ }^{5}$, José Carlos González \\ Hidalgo ${ }^{6}$, David Granado García ${ }^{1}$, Askoa Ibisate González de Matauco7, \\ Carmelo Marcén Albero ${ }^{8}$, Daniel Mora Mur ${ }^{2}$, Estela Nadal Romero6, \\ Alfredo Ollero Ojeda ${ }^{6}$, Miguel Sánchez Fabre ${ }^{6}$, Miguel Ángel Saz \\ Sánchez ${ }^{6}$ y Roberto Serrano Notivoli ${ }^{9}$ \\ 1 Ecoter S.C. info@ecoter.com.es, 2 Mastergeo S.L., \\ 3 Dpto. de Derecho Público, Universidad de Extremadura \\ 4 UTE Información Hidrológica Ebro, 5 Agencia Estatal de Meteorología \\ 6 Dpto. de Geografía y Ordenación del Territorio, Universidad de Zaragoza \\ 7 Dpto. de Geografía, Prehistoria y Arqueología, Universidad del País Vasco UPV/EHU \\ 8 I.E.S. Miguel Catalán (Zaragoza), 9 Estación Experimental de Aula Dei (CSIC)
}

\begin{abstract}
Resumen: Intensas precipitaciones en los días 19 y 20 de octubre de 2012 generaron crecidas en toda la red fluvial de los afluentes pirenaicos de la cuenca del Ebro. Se presentan brevemente los registros de precipitación alcanzados, las distintas respuestas hidrológicas y las principales situaciones de riesgo. Se reflexiona sobre las consecuencias de estas crecidas y se plantea la necesidad de sustituir las actuaciones de urgencia al uso por una gestión del riesgo basada en la ordenación de los espacios inundables, en consonancia con los principios de la Directiva 2007/60/CE de gestión del riesgo de inundación.
\end{abstract}

Palabras clave: precipitación, cauce, crecida, inundaciones, gestión del riesgo, Directiva 2007/60/CE.

\begin{abstract}
On $19^{\text {th }}$ and $20^{\text {th }}$ October of 2012 an event of intense rainfall triggered flooding processes in the whole watershed of the Pyrenean tributaries of the Ebro basin. A brief description of rainfall data, hydrological responses and risk situations is presented. A reflection of the consequences of these floods is presented along with a necessity to change the emergency measures for risk management based on the adequate
\end{abstract}


flood-prone areas management as requires the Floods Directive, 2007/60/CE on the assessment and management of flood risks.

Keywords: rainfall, stream channel, flood, flooding processes, risk management, 2007/60/EC Directive.

\section{Introducción, metodología y área de estudio}

El presente trabajo tiene como objetivo describir la situación extrema de precipitaciones y crecidas de octubre de 2012 y extraer las lecciones que nos deja, que deben servir para la necesaria mejora en la gestión del riesgo. Es presentado por científicos, profesionales y docentes preocupados por estas temáticas y por las situaciones concretas de riesgo que se han puesto en evidencia.

Para el presente análisis no se ha establecido una metodología específica. En espera de un proceso de investigación completo, este trabajo ha sido elaborado menos de un mes después del evento descrito, por lo que simplemente se ha llevado a cabo una recopilación de información (datos meteorológicos de la Agencia Estatal de Meteorología, datos hidrológicos del Sistema Automático de Información Hidrológica de la cuenca del Ebro, documentos, noticias de prensa y algunas medidas de campo) y una interpretación básica, que se ha completado con representaciones gráficas sencillas: hidrogramas, cartografía, fotos.

El área de estudio se ha restringido al ámbito aragonés de la zona pirenaica y prepirenaica afectada, correspondiendo a las cuencas de los ríos Aragón, Arba, Gállego y Cinca, todos ellos afluentes del río Ebro por la margen izquierda (figura 1).

En el Pirineo aragonés hay importantes antecedentes de precipitaciones intensas (García Ruiz et al., 2000). La respuesta hidrológica suele ser rápida y con volúmenes relevantes (García Ruiz et al., 1996, 2002). En todo Aragón hay numerosos núcleos de población expuestos a las inundaciones fluviales (Domenech et al., 2008, 2011). Así pues, estamos hablando de un riesgo recurrente, el más frecuente en nuestro ámbito de estudio. La situación de octubre de 2012 puede calificarse de extrema, principalmente en la cuenca alta del Aragón, por los elevados volúmenes de precipitación y caudal registrados, pero en absoluto puede considerarse excepcional. Se ha evitado conscientemente aportar cálculos de periodos de retorno, considerados por los autores poco válidos e incluso contraproducentes en la gestión del riesgo, ya que pueden generar visiones irreales y conflictos (Ayala, 2002). 


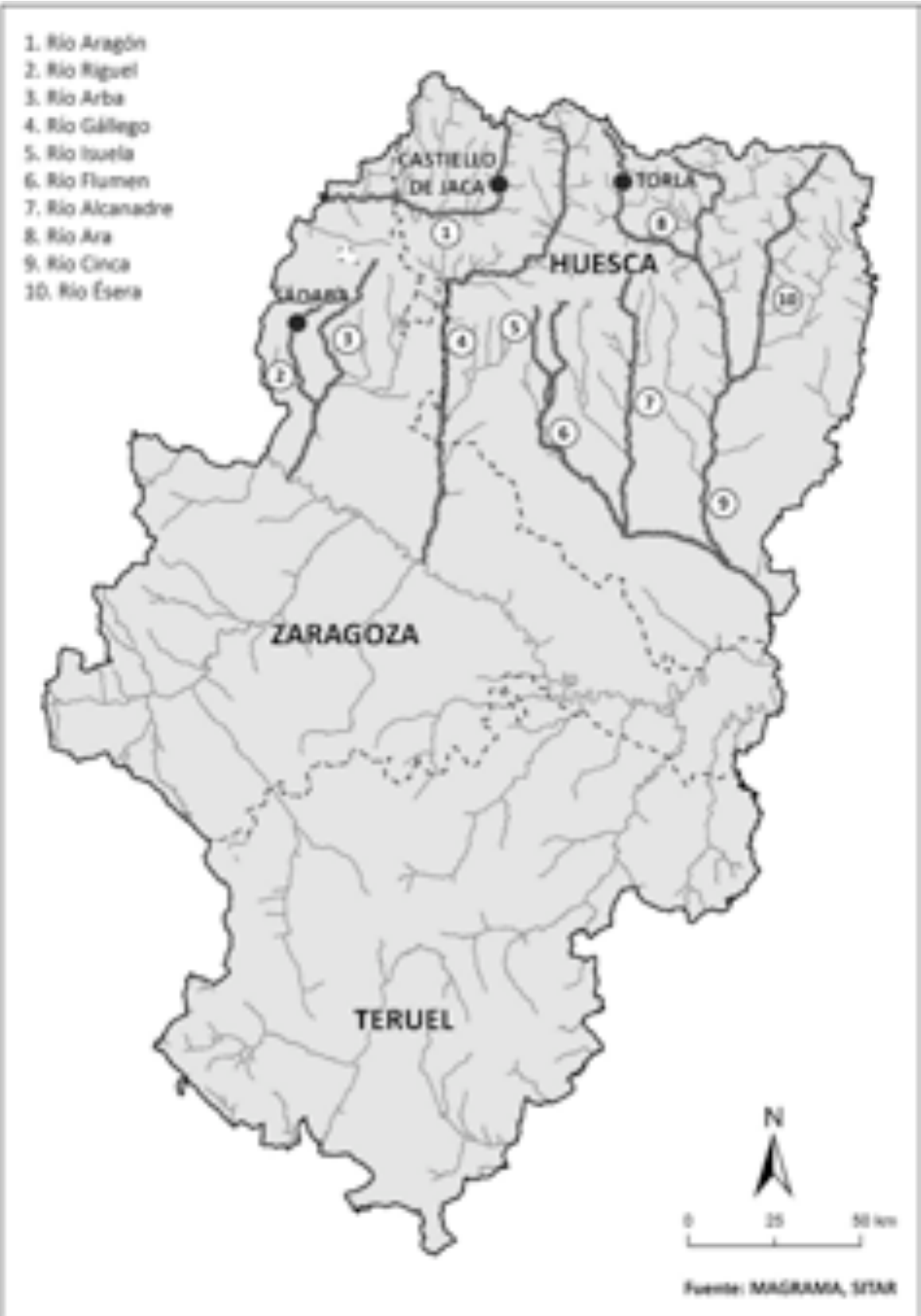

Figura 1. Principales cursos fluviales afectados y puntos de riesgo más significativos. 


\section{Las precipitaciones del 19 al 21 de octubre de 2012}

La situación sinóptica de los episodios de precipitación comenzó el día 19 de noviembre cuando una vaguada en altura dispuesta en sentido meridiano desde las islas británicas hasta las costas occidentales peninsulares dio lugar al primer evento. La situación en superficie quedaba dominada por una baja localizada al NW peninsular, con la presencia de un frente frío que se correspondía en altura con el ramal de salida de la vaguada, que a lo largo del episodio fue iniciando una transformación hacia una depresión en niveles altos, estrechándose y cerrándose las líneas de corriente, aislando un embolsamiento de aire frío en altura localizado al sur peninsular, origen del segundo evento de precipitación a partir de mediodía del 20 de octubre (figura 2). En este segundo evento la situación en superficie dio origen a un cambio de las direcciones de flujo dominante, que pasaron a ser E-SE, siendo un ejemplo del llamado frente de retroceso (Estrela et al., 2002) u oclusión sobre el valle del Ebro.

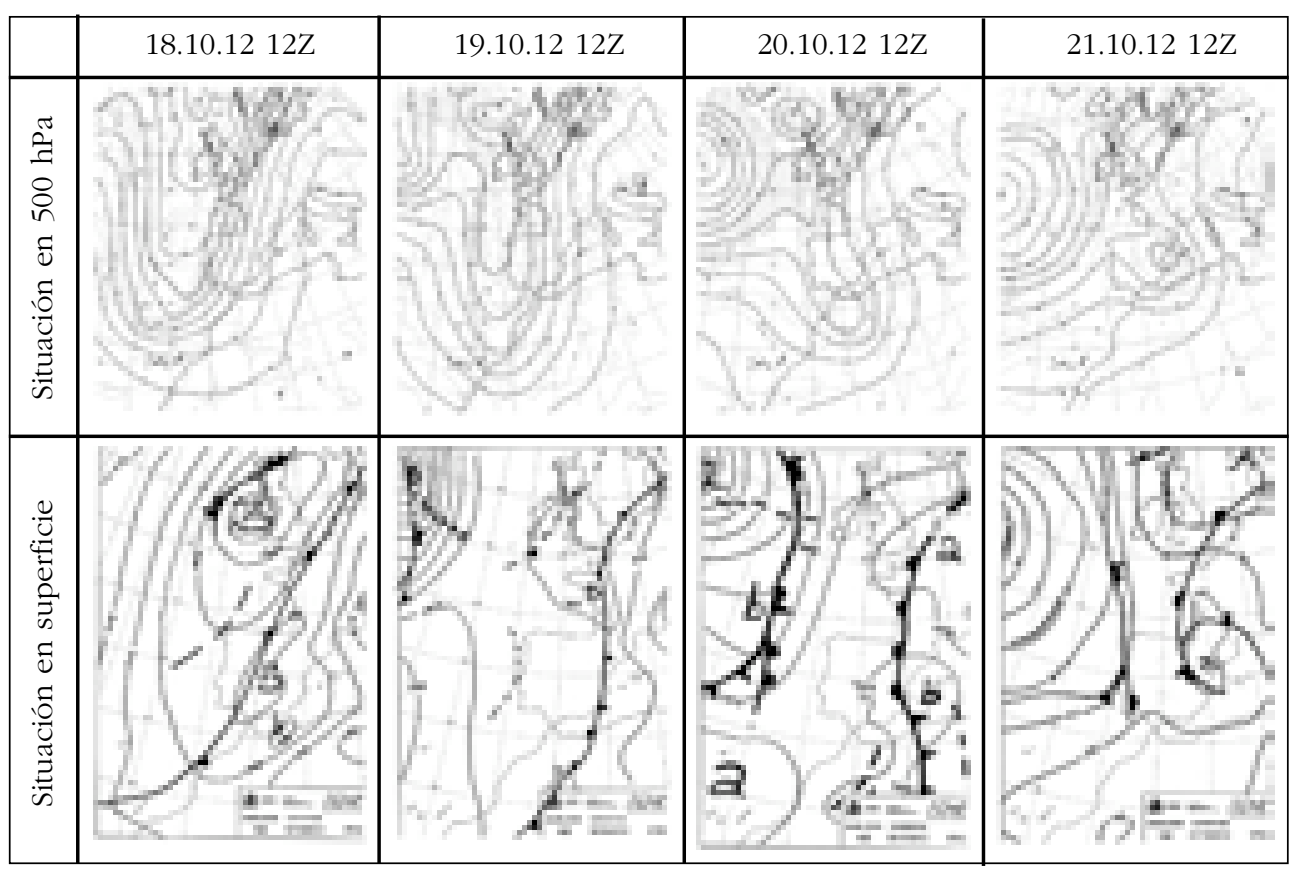

Figura 2. Situación sinóptica en altura (500 hPa) y superficie a lo largo del episodio (Fuente: AEMET). 
Por sus características sinópticas, y por las consecuencias producidas que se detallarán a continuación, se trata, según la clasificación de este tipo de eventos (Espejo, 2008), de una situación claramente equinoccial, con un acusado dinamismo y circulación ciclónica, parecida a otras que produjeron inundaciones en los ríos pirenaicos en noviembre de 1966 y 1967, así como en noviembre de 1982.

Los observatorios de la Agencia Estatal de Meteorología (AEMET) mostraron que la precipitación de mayor intensidad se registró el sábado 20, con una media de 44,7 $1 / \mathrm{m}^{2}$ para las 136 estaciones comprendidas en el Pirineo y toda la mitad Norte de la comunidad aragonesa. El dato medio de precipitación acumulada para los días 19 a 21 es de 88,9 1/ $\mathrm{m}^{2}$, valor especialmente significativo teniendo en cuenta que la precipitación media del mes de octubre en Aragón (periodo 1971-2000) es de 54,3 1/ $\mathrm{m}^{2}$.

El mapa de distribución de las lluvias (figura 3) muestra una agrupación en la zona del Pirineo occidental, especialmente en el Valle del Aragón y en el Valle de Hecho, donde las concentraciones de precipitación superaron los 200 1/ $\mathrm{m}^{2}$.

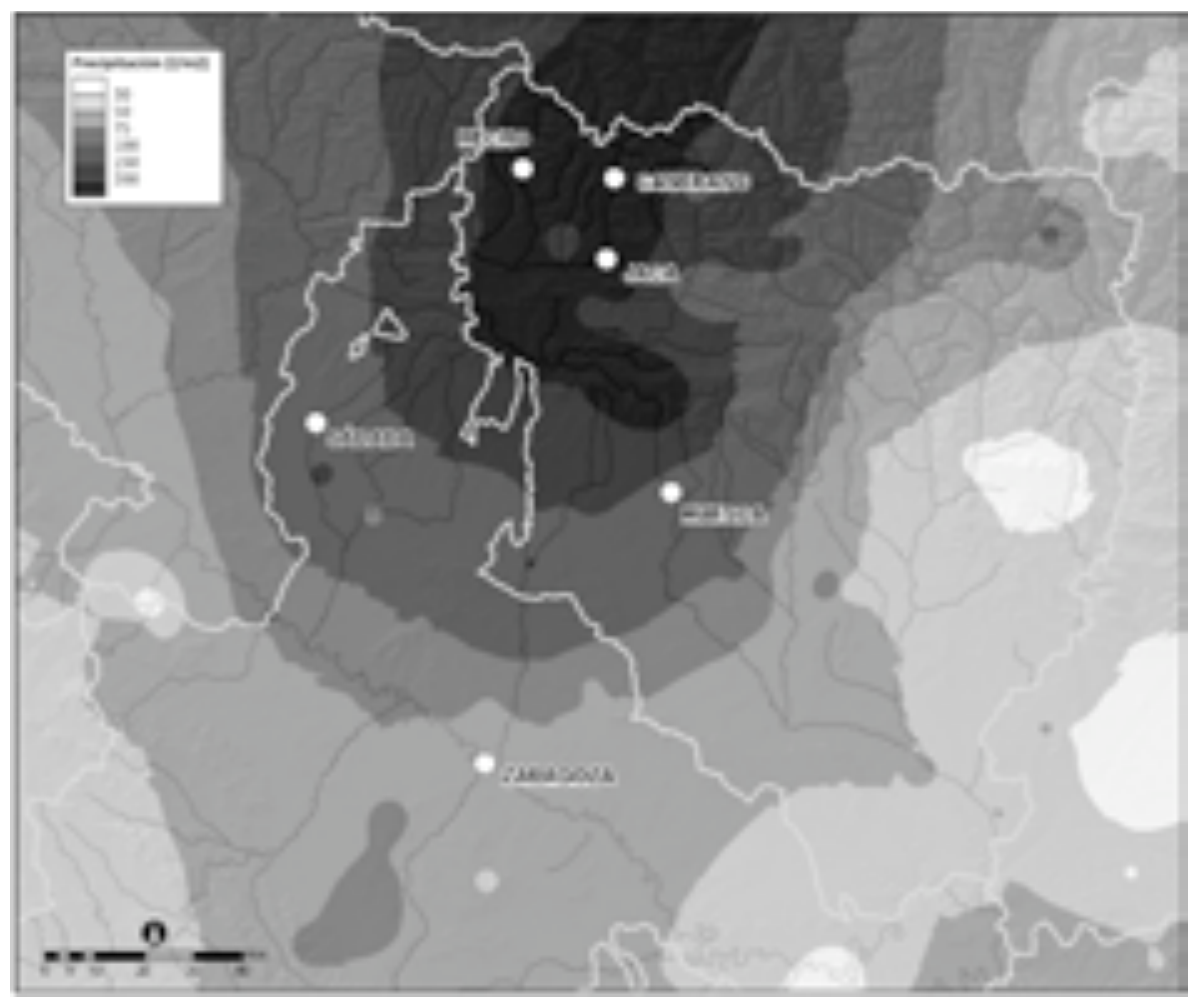

Figura 3. Mapa de distribución e intensidad de la precipitación acumulada en los días 19, 20 y 21 de octubre. 
El reparto espacial de las precipitaciones refleja en general una progresión negativa desde las cabeceras de los valles occidentales hacia el resto del territorio, aunque también en zonas bajas hubo algunos sectores con mayor cantidad de lluvia, como Sádaba o Huesca, con precipitaciones superiores a $751 / \mathrm{m}^{2}$ en los tres días de máxima intensidad.

En una exploración de la distribución temporal, se observa que la intensidad en las zonas de mayor precipitación fue mucho mayor el día 19, mientras que otras apenas recibieron nada. En el conjunto del territorio, el día 20 se repartió mucho más, lloviendo homogéneamente y con intensidad moderada (figura 4). El observatorio de Canfranc fue el que mayor precipitación registró, con 222,3 1/ $\mathrm{m}^{2}$ el día 19 . El mismo día se registraron las mayores intensidades de los tres días de temporal en Bescós de Garcipollera $\left(215,7 \mathrm{l} / \mathrm{m}^{2}\right)$, Jaca $\left(200 \mathrm{l} / \mathrm{m}^{2}\right)$, Arguis $\left(192,8 \mathrm{l} / \mathrm{m}^{2}\right)$, Villanúa $\left(187 \mathrm{l} / \mathrm{m}^{2}\right)$, y Hecho $\left(149,2 \mathrm{l} / \mathrm{m}^{2}\right)$.

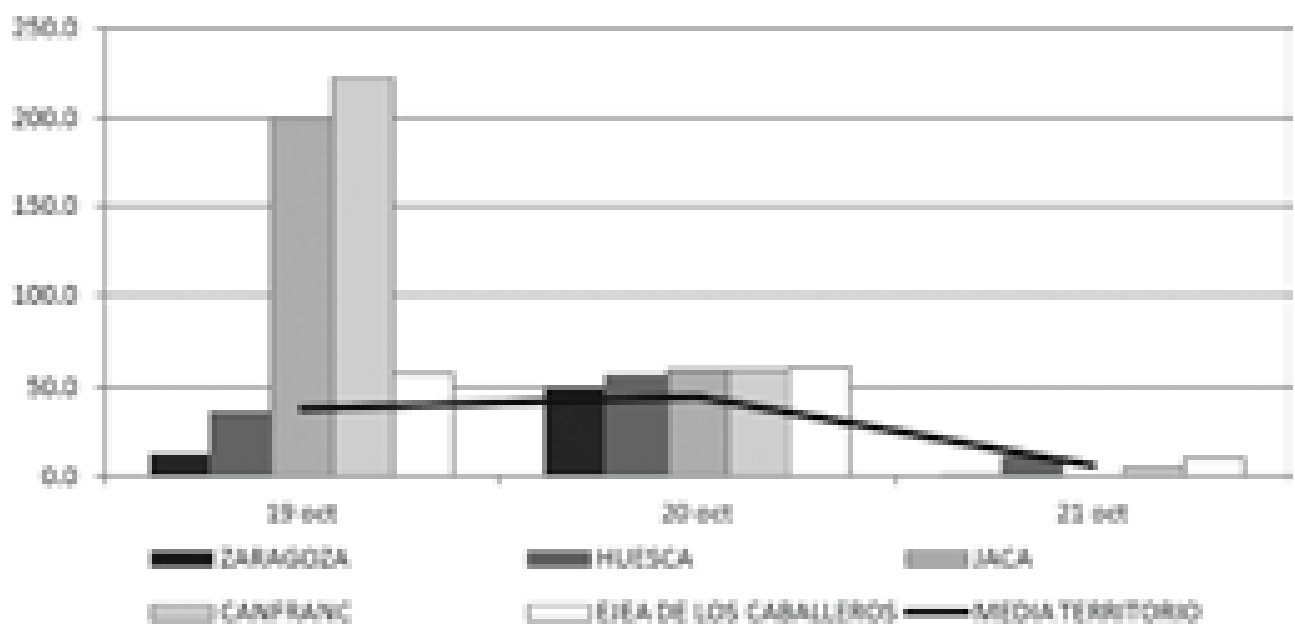

Figura 4. Distribución temporal de la precipitación en estaciones significativas y para todo el territorio.

\section{Respuesta hidrológica}

Antes de llegar sus efectos a los cauces fluviales, las intensas precipitaciones generaron numerosos e intensos procesos geomorfológicos en las laderas, constatándose visualmente la activación de debris flows en las áreas del flysch de las cuencas del Aragón y alto Gállego, así como procesos de movilización de sedimentos en cárcavas y badlands. 
Como ejemplo bien estudiado, los efectos de las lluvias se han observado muy notables en la cuenca experimental de Araguás, gestionada por el Instituto Pirenaico de Ecología (CSIC), próxima a Jaca, en la subcuenca del río Lubierre próximo a su desembocadura en el río Aragón. La respuesta hidrológica registrada durante el evento está caracterizada por rápidas respuestas de caudal, con rápidos ascensos y descensos de la curva del hidrograma, reproduciendo con bastante fidelidad la forma del hietograma. La precipitación total registrada en la estación de aforo de la cuenca experimental fue de $140,6 \mathrm{l} / \mathrm{m}^{2}$ y la escorrentía total generada fue de $42,33 \mathrm{l} / \mathrm{m}^{2}$, con un caudal máximo de 3931,7 1/s/ $\mathrm{km}^{2}$, registrado el sábado 20 a las 15:40 horas. La producción de sedimento fue muy elevada, siendo la máxima concentración próxima a los $500 \mathrm{~g} / 1 \mathrm{y}$ la producción de sedimento en suspensión de 1392,17 Tm/ km². Además, se observaron pequeños deslizamientos y movimientos en masas en laderas con fuertes pendientes (figura 5). La escorrentía registrada es la máxima generada en una crecida desde la entrada en funcionamiento de la estación de aforo en octubre de 2005 y los valores de caudal y de sedimento corresponden con el segundo máximo registrado en estos 7 años.
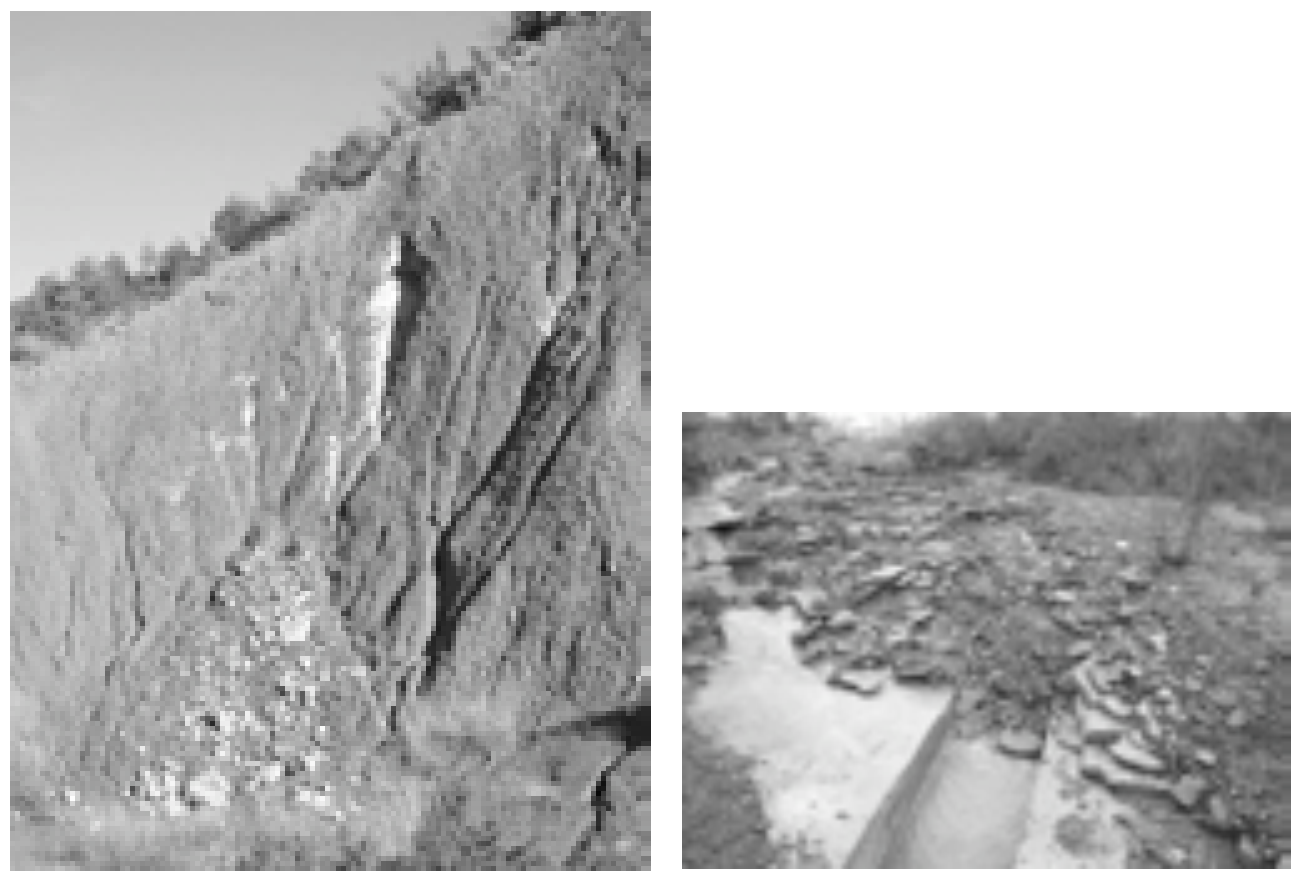

Figura 5. Dos imágenes de la movilización de sedimentos en la cuenca experimental de Araguás como consecuencia de las precipitaciones registradas. 
Las intensas precipitaciones acumuladas dieron lugar a importantes crecidas en las cuencas del Aragón, Arba, Gállego y Cinca. Los registros obtenidos en diferentes estaciones de aforo de sus ríos, a pesar de algunas discontinuidades, permiten analizar las características de dichas crecidas, salvo en aquellos aforos donde la propia intensidad de las aportaciones inhabilitó el instrumental de toma, registro y comunicación de datos de las estaciones, como sucedió en Sádaba (Río Riguel, afluente del Arba). Se han elaborado hidrogramas de la evolución de la crecida en las cuencas del Aragón, Gállego y Cinca.

En el hidrograma correspondiente a la cuenca del Aragón (figura 6) se incluyen los datos de aforo de Canfranc, Jaca y Martes, pertenecientes al río Aragón, y de Javierregay, relativos al río Aragón Subordán. Muestra un rápido ascenso de los caudales desde mediodía del día 19 de octubre y una curva de ascenso integrada por diversos "dientes de sierra", muy marcados en Jaca y Martes, asociados al ritmo e intensidad con la que se iban produciendo las precipitaciones. El pico de la crecida se alcanzó en Canfranc a las 8 horas del día $20\left(74,38 \mathrm{~m}^{3} / \mathrm{s}\right)$, habiéndose obtenido un valor muy similar, $72,43 \mathrm{~m}^{3} / \mathrm{s}$, a última hora de la tarde del día 19. En Jaca y Martes, donde hay algunas discontinuidades en los registros, la cresta de la crecida se constató a primera hora del día 21, con valores muy significativos de $635 \mathrm{~m}^{3} / \mathrm{s}$ (máximo

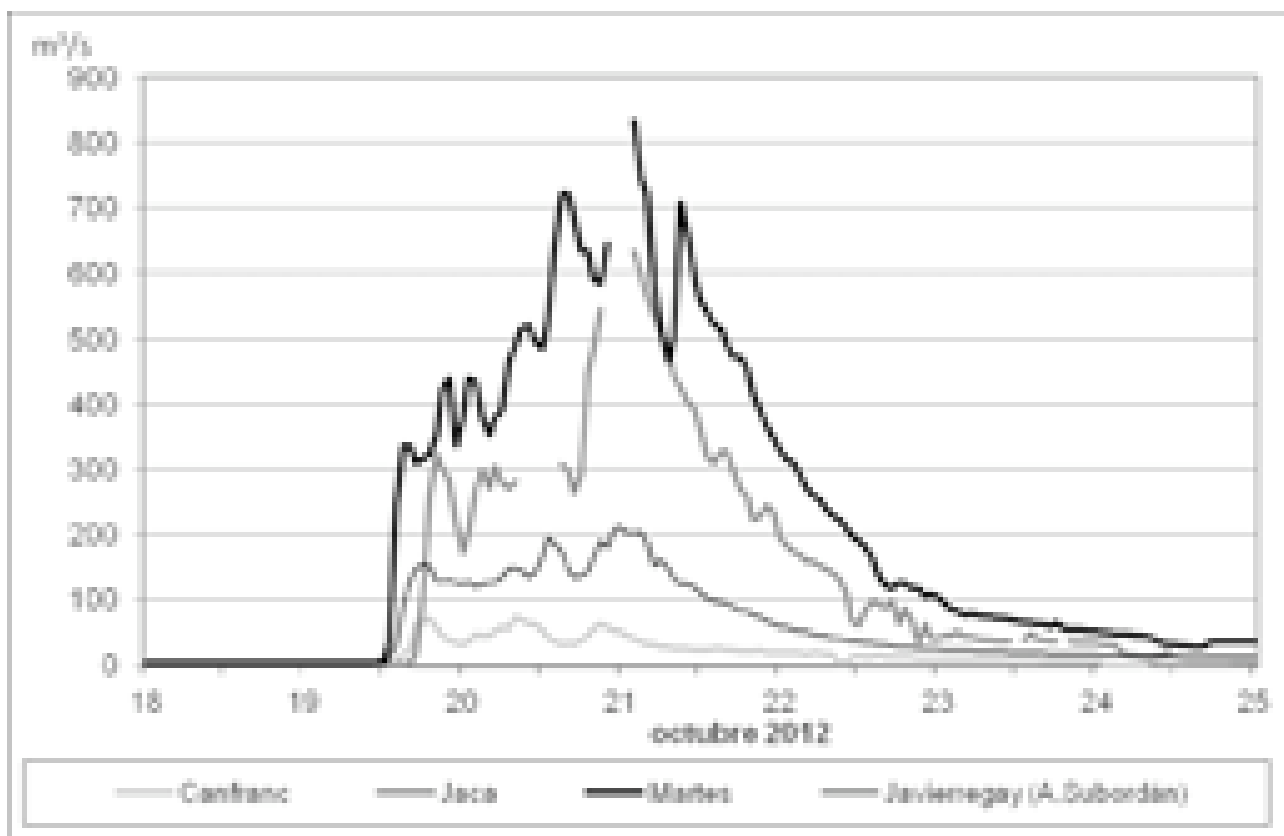

Figura 6. Hidrograma de la crecida del río Aragón y su afluente el Aragón Subordán. (Elaboración propia a partir de datos del SAIH). 
registro histórico) y $833 \mathrm{~m}$ 3/s, respectivamente. Por su parte, el río Aragón Subordán tuvo su pico de crecida en el tránsito del día 20 al $21\left(213 \mathrm{~m}^{3} / \mathrm{s}\right)$. La curva de descenso evidencia la rápida disminución del caudal, especialmente en los aforos de Jaca y Martes, apreciándose en este último una interrupción del descenso y un nuevo ascenso de los caudales durante algunas horas del día 21, al que sigue ya el descenso progresivo y continuado de los mismos. En estos dos aforos la curva de descenso se completa hacia la mitad del día 22. Se puede considerar que la crecida duró tres días, desde mediodía del 19 a mitad del 22.

En la cuenca del Gállego, tanto el río Gállego en Anzánigo como su afluente el Sotón en Ortilla muestran una serie de pulsaciones en la evolución de la crecida, desde la tarde del día 19 al día 21, que traducen las variaciones de intensidad de las precipitaciones. A través de ellas, el río Sotón marca dos máximos durante el día 20 de valores muy similares $\left(191,32 \mathrm{~m}^{3} / \mathrm{s}\right.$ y $\left.188,51 \mathrm{~m}^{3} / \mathrm{s}\right)$. A su paso por Anzánigo el río Gállego dejó un registro máximo para esta crecida de $609,1 \mathrm{~m}^{3} / \mathrm{s}$, a las $12 \mathrm{~h}$. del día 20, si bien falta algún dato previo al momento de ese pico. Menos oscilaciones marcan los caudales en Ardisa y Zuera, ya que en estos puntos la evolución natural de la crecida está modificada por la gestión de varios embalses. En Ardisa la curva de ascenso de caudal se inició durante la mañana del día 20, conduciendo en sólo 9 horas a un pico secundario $\left(597,77 \mathrm{~m}^{3} / \mathrm{s}\right)$ y otras 9 horas más tarde al pico principal

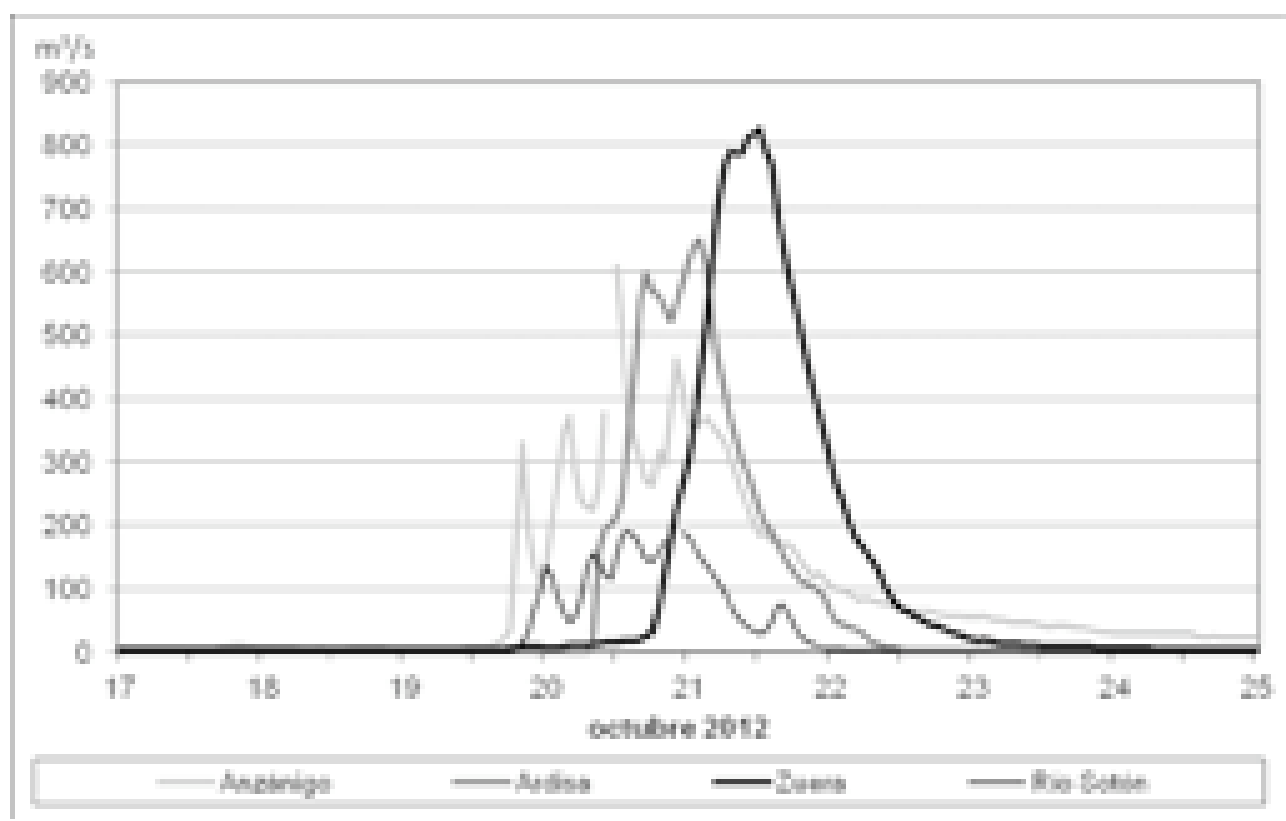

Figura 7. Hidrograma del episodio de crecida en diferentes aforos del río Gállego (Anzánigo, Ardisa y Zuera) y en su afluente el río Sotón. (Elaboración propia a partir de datos del SAIH). 

J. C. González, D. Granado, A. Ibisate, C. Marcén, D. Mora...

de $651,69 \mathrm{~m} 3 / \mathrm{s}$. En Zuera el incremento de caudal que fluye por el Gállego se acelera durante la tarde del día 20 hasta alcanzar un pico de 826,48 $\mathrm{m}^{3} / \mathrm{s}$ al mediodía del día 21, sólo 10 horas después del principal registrado en Ardisa. Si en estos dos aforos del Gállego la curva de ascenso es muy pronunciada, no reflejando las variaciones de intensidad de las precipitaciones durante este episodio, también lo es la curva de descenso que, de forma progresiva y sin repuntes, se completa en aproximadamente un día. En tanto que en el aforo de Anzánigo y en el del río Sotón la crecida se inició poco después del comienzo de las precipitaciones, en Ardisa y en Zuera se aprecia un notable retraso.

Partiendo de unos caudales extraordinariamente bajos, distintos afluentes del río Cinca experimentaron notables crecidas a partir de las precipitaciones registradas durante varios días del mes de octubre. El hidrograma (figura 8) recoge la evolución del episodio de crecida en varios de esos afluentes, así como en el propio río Cinca a su paso por Fraga.

El río Ara incrementó bruscamente su caudal desde las 12 a las 18 horas del día 19 de octubre, para moderar algo el progresivo ascenso durante las horas siguientes y volver a acelerarlo en la madrugada del día 20 hasta alcanzar el pico principal del episodio de crecida, $426 \mathrm{~m}^{3} / \mathrm{s}$ a las 10 horas de ese día. Se inicio entonces una pronunciada curva de descenso que no llegó a completarse, ya que poco antes de finalizar el día el nivel de las aguas subió de forma brusca hasta un pico secundario de $399,54 \mathrm{~m}^{3} / \mathrm{s}$ en la primera hora del día 21. De nuevo comenzó el descenso de caudal para completarse las curvas de descenso y de agotamiento. El episodio de crecida se había extendido, básicamente, desde mitad del día 19 a final del día 23, reflejando muy claramente la respuesta a dos fases de mayor intensidad de las precipitaciones.

Los ríos Flumen y Guatizalema muestran unas curvas con trazado muy similar, aunque con valores más altos el Flumen, por lo que la crecida dura algo más, desde mitad del día 20 a mitad del día 22. En ambos casos la cresta de crecida es suave y bastante prolongada en el tiempo. El mayor registro del Flumen son los $73,6 \mathrm{~m}^{3} / \mathrm{s}$ que se repitieron en varias observaciones en el tránsito de los días 20 y 21, así como en la madrugada del día 21. El valor más alto alcanzado por el río Guatizalema quedó en $32,2 \mathrm{~m}^{3} / \mathrm{s}$.

Las aguas del río Alcanadre empezaron a crecer en la tarde del día 20 hasta superar los $50 \mathrm{~m}^{3} / \mathrm{s}$. Tras un pequeño retroceso, iniciaron un ascenso más prolongado que se acentuó en la tarde del día 21 y las primera horas del 22 hasta producir el pico principal del episodio, 292,04 $\mathrm{m}^{3} / \mathrm{s}$. La reducción de la intensidad de las precipitaciones determinó un descenso momentáneo del caudal, que repuntó posteriormente para generar un pico secundario de $278,7 \mathrm{~m} 3 / \mathrm{s}$, todo ello durante el día 22 de octubre. Desde entonces se inició un descenso continuado de los caudales. 
La curva que dibuja la evolución del caudal del río Cinca en Fraga es un calco de la comentada del Alcanadre en Ballobar, simplemente con un ligero retraso, 2 ó 3 horas, en el momento de producirse los diferentes hitos del desarrollo de la crecida. Además, los valores máximos de caudal alcanzados $\left(215,99 \mathrm{~m}^{3} / \mathrm{s}\right.$ pico principal, $192,35 \mathrm{~m} 3 / \mathrm{s}$ pico secundario) son también más bajos que los obtenidos en el Alcanadre. De ello se deduce que la crecida apreciada en el Cinca, a su paso por Fraga, durante los días 20 a 24 de octubre, está motivada por la aportación realizada por el río Alcanadre, habiéndose producido una laminación efectiva del caudal entre Ballobar y Fraga gracias al desbordamiento.

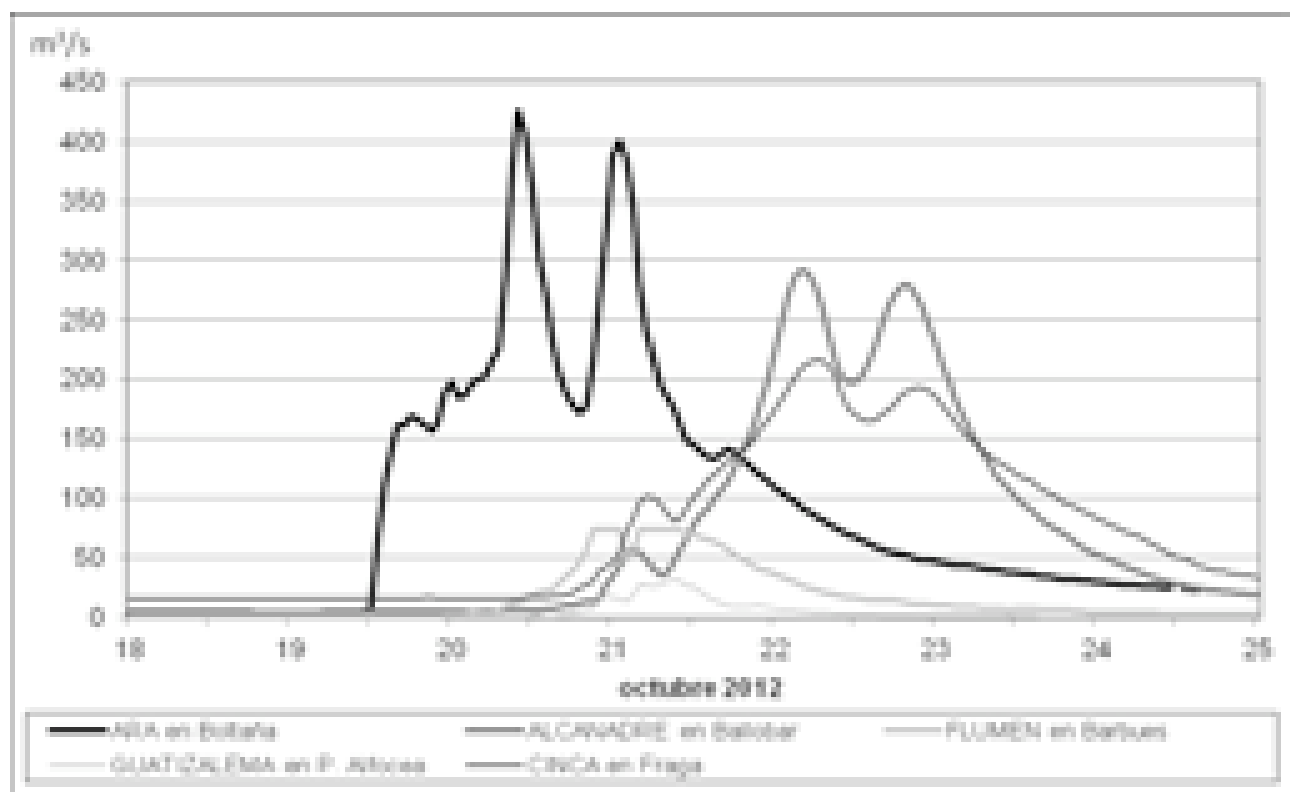

Figura 8. Hidrograma de la crecida en varios ríos de la cuenca del Cinca. (Elaboración propia a partir de datos del SAIH).

Estas crecidas pirenaicas han supuesto una magnífica inyección de naturalidad y auto-recuperación para nuestros maltratados ríos. Después de años sin crecidas, ni siquiera pequeñas (eliminadas por los embalses), estas avenidas han podido movilizar sedimentos y probablemente han renovado poblaciones de seres vivos, han frenado a especies invasoras, han creado nuevos hábitats y han permitido rejuvenecer y mantener a raya el desarrollo vegetal en los cauces provocado por los embalses reguladores de aguas arriba. Así pues, estas crecidas han debido resultar, sin duda, enormemente beneficiosas para nuestros ríos, es decir, para nuestro medio ambiente $\mathrm{y}$, por tanto, para todos nosotros a medio y largo plazo. Este aspecto necesario y 
beneficioso de estas crecidas e inundaciones no ha sido mencionado en los medios de comunicación.

Ahora bien, buena parte de los caudales y sedimentos movilizados han acabado retenidos en los embalses, al encontrarse éstos en niveles muy bajos tras un verano especialmente seco, almacenándose la mayor parte de la escorrentía generada. En consecuencia, la crecida no ha podido llegar al colector principal, el río Ebro, muy necesitado de caudales extra, ya que presenta problemas cada vez mayores de crecimiento de algas en el cauce, de renovación de hábitats, de sequía en los sotos, de descenso en el freático que está afectando a espacios como el Galacho de la Cartuja aguas abajo de Zaragoza, etc.

\section{Daños y situaciones de riesgo}

Las precipitaciones y crecidas registradas no causaron daños personales. Hay que destacar que los sistemas de previsión, alerta y emergencia funcionaron correctamente.

La primera situación de riesgo puesta en evidencia por estas precipitaciones extremas fue la del río Riguel en Sádaba, localidad zaragozana de la comarca de las Cinco Villas, en la mañana del día 19 (figura 9). El río superó ampliamente las dimensiones de su canalización urbana y se desbordó en la villa causando daños en el casco urbano. La sección del cauce es amplia (unos 35 metros) aguas arriba del puente de la carretera A-127 que atraviesa el municipio, mientras que la sección aguas abajo del mismo se reduce considerablemente. El caudal de crecida en este punto desbordó la canalización generando inundaciones en comercios, locales y viviendas. El efecto más destacable fue la inundación del Colegio Público Rural Agrupado "Los Bañales", evaluándose los daños sufridos en $400.000 €$ Su reconstrucción va a ser financiada por la Diputación Provincial de Zaragoza. El edificio se encuentra en la margen derecha del río, en una orilla activa y por tanto en una clara situación de exposición, pero no se ha planteado su traslado. La fuerza de la corriente arrasó la estación de aforos que se encontraba aguas abajo del colegio, la cual dejó de trasmitir datos en tiempo real a la red SAIH a las 9:30 h, cuando el nivel registrado era de 3,49 m. Se estima que la altura del agua pudo alcanzar hasta los $6 \mathrm{~m}$ en este punto. Se registraron también daños en viales, caminos y fincas agrícolas. Aguas abajo, el río Arba, colector principal del Riguel, asistió a una crecida notable pero no generó daños relevantes.

La situación más llamativa fue la protagonizada por el río Aragón en Castiello de Jaca, donde la crecida derribó un edificio unifamiliar adosado de una urbanización construida sobre el espacio fluvial (figura 10). La figura 11 muestra con claridad la evolución reciente del cauce y las causas humanas de la situación de riesgo: 


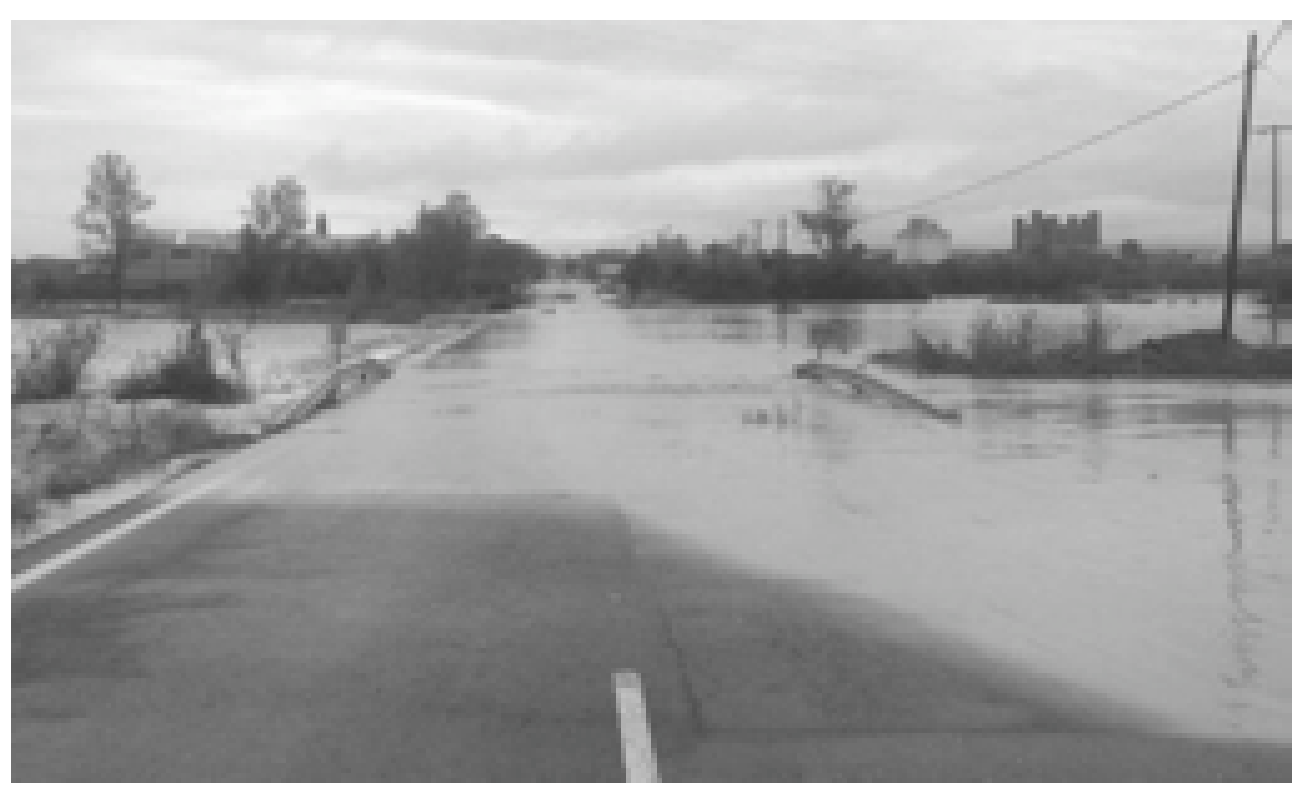

Figura 9. La carretera A-127 cortada a la entrada de Sádaba.

- En la ortofoto de 1998 se observa que el río Aragón se dividía en dos cauces funcionales, uno principal a la derecha de la imagen y otro secundario a la izquierda. La vegetación de ribera ocupaba las márgenes de ambos canales y colonizaba con formaciones maduras la isla central.

- En la foto de 2009 ya se ha taponado artificialmente el antiguo cauce secundario (en línea discontinua) y ya se ha construido la urbanización "El Molino" sobre la antigua orilla.

- La fotografía aérea de 2012 fue tomada por la Confederación Hidrográfica del Ebro un día después de la crecida. Se observa que el río Aragón ha retomado su antiguo cauce secundario convirtiéndolo en principal, ya que al ser más corto y de mayor pendiente fue más eficiente para evacuar los caudales de crecida. Mientras, el anterior cauce principal quedó taponado por la acumulación de sedimentos gruesos depositados por la crecida. En esta masa sedimentaria predomina lo arrastrado por el río desde aguas arriba (comprobado en campo por el elevado rodamiento de bloques y cantos), pero hay también una muy pequeña porción procedente del deslizamiento paralelo a la crecida que se produjo en la ladera de la margen izquierda. 


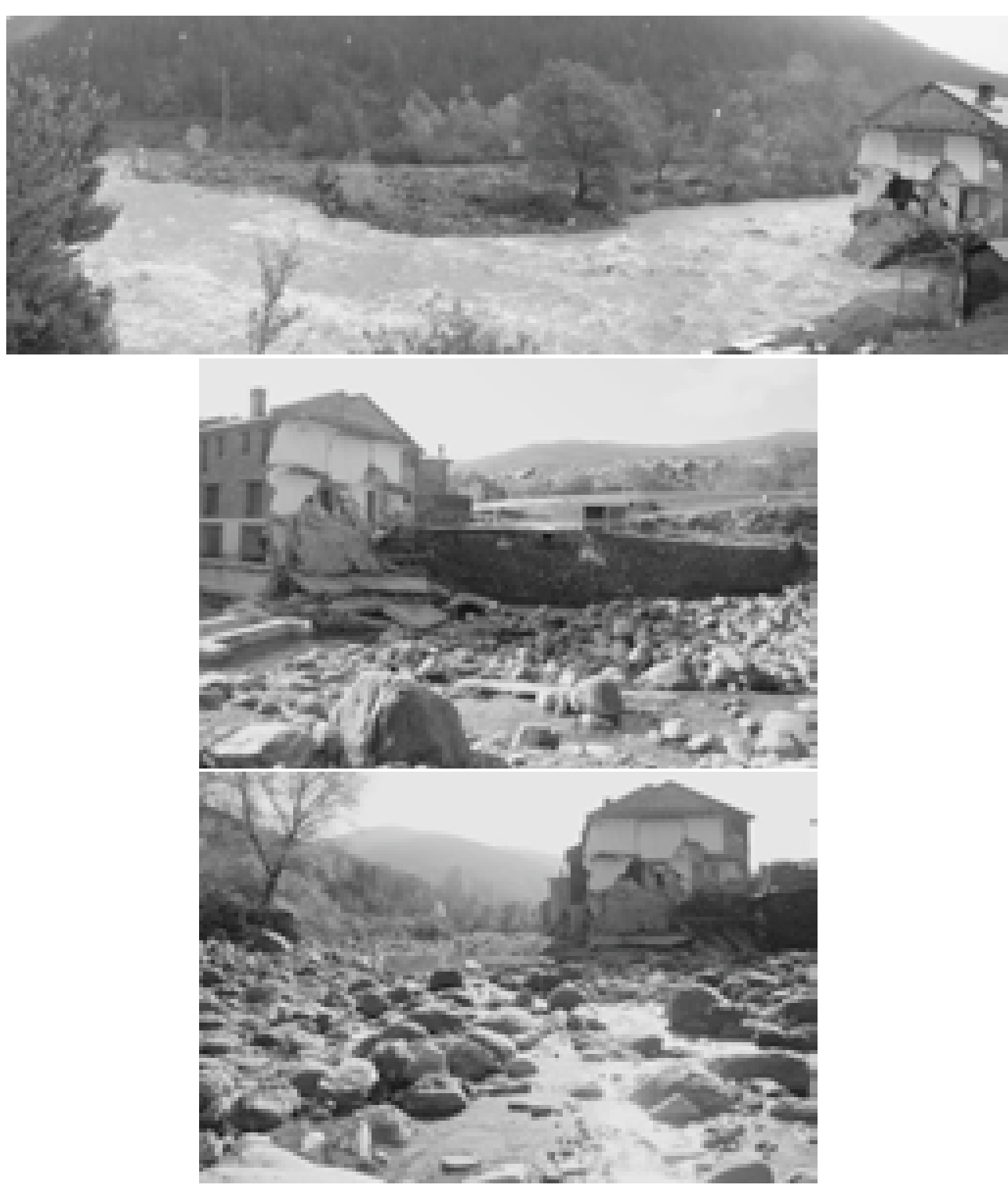

Figura 10. Tres perspectivas del unifamiliar construido en el cauce y destruido por la crecida. La primera imagen está tomada antes del desvío del cauce por la C.H.E., las otras dos son posteriores a la fase inicial de las obras. 


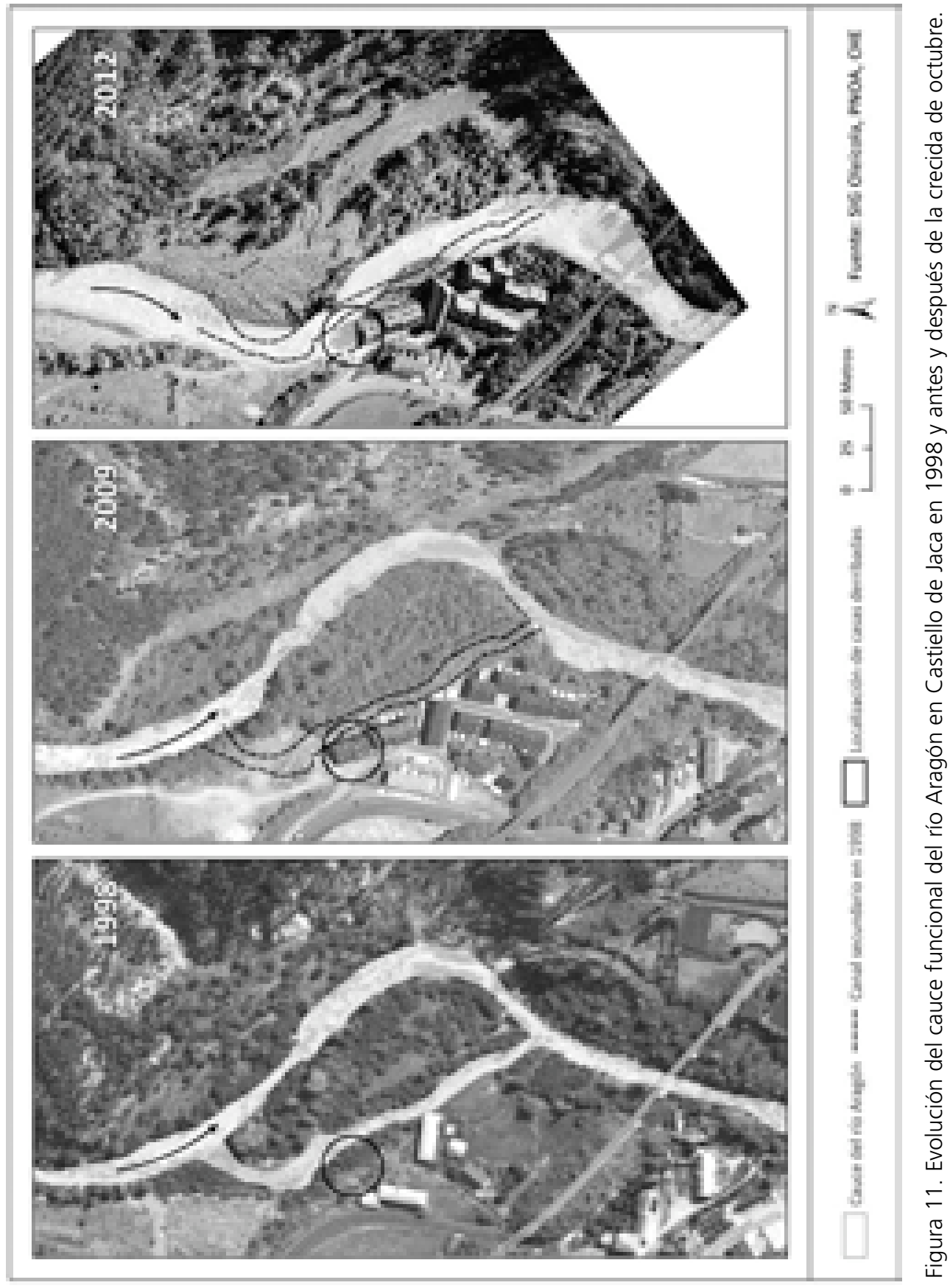



J. C. González, D. Granado, A. Ibisate, C. Marcén, D. Mora...

Desde la Confederación Hidrográfica del Ebro se atribuyó a este pequeño deslizamiento (figura 12) el desvío de la corriente con la consecuencia de que ésta retomara su antiguo cauce secundario. Sin embargo, una vez analizados visualmente en campo tanto las proporciones del deslizamiento como el material aportado por éste como el material depositado por el río en toda el área, la hipótesis del desvío debe quedar totalmente descartada. La crecida, al ser importante, ocupó todo el cauce, el principal y el secundario, que es el que estaba debajo de la urbanización. Al bajar las aguas el caudal de crecida tomó ese cauce antiguamente secundario de los edificios simplemente por ser más recto y contar con mayor pendiente. Hay que tener en cuenta además que la corriente viene de un rebote con la margen izquierda, en concreto contra la ladera afectada por el deslizamiento, pero, independientemente de que haya habido deslizamiento o no, el resultado de dicho rebote es dirigir la corriente hacia la margen derecha. Y precisamente los unifamiliares que cayeron, los de aguas arriba (marcados con un círculo en la figura 11), se encontraban al borde del punto de máxima inflexión del meandro del cauce secundario. En crecidas antiguas, aunque no hemos podido obtener ningún documento que lo ratifique, el proceso debió de ser similar.

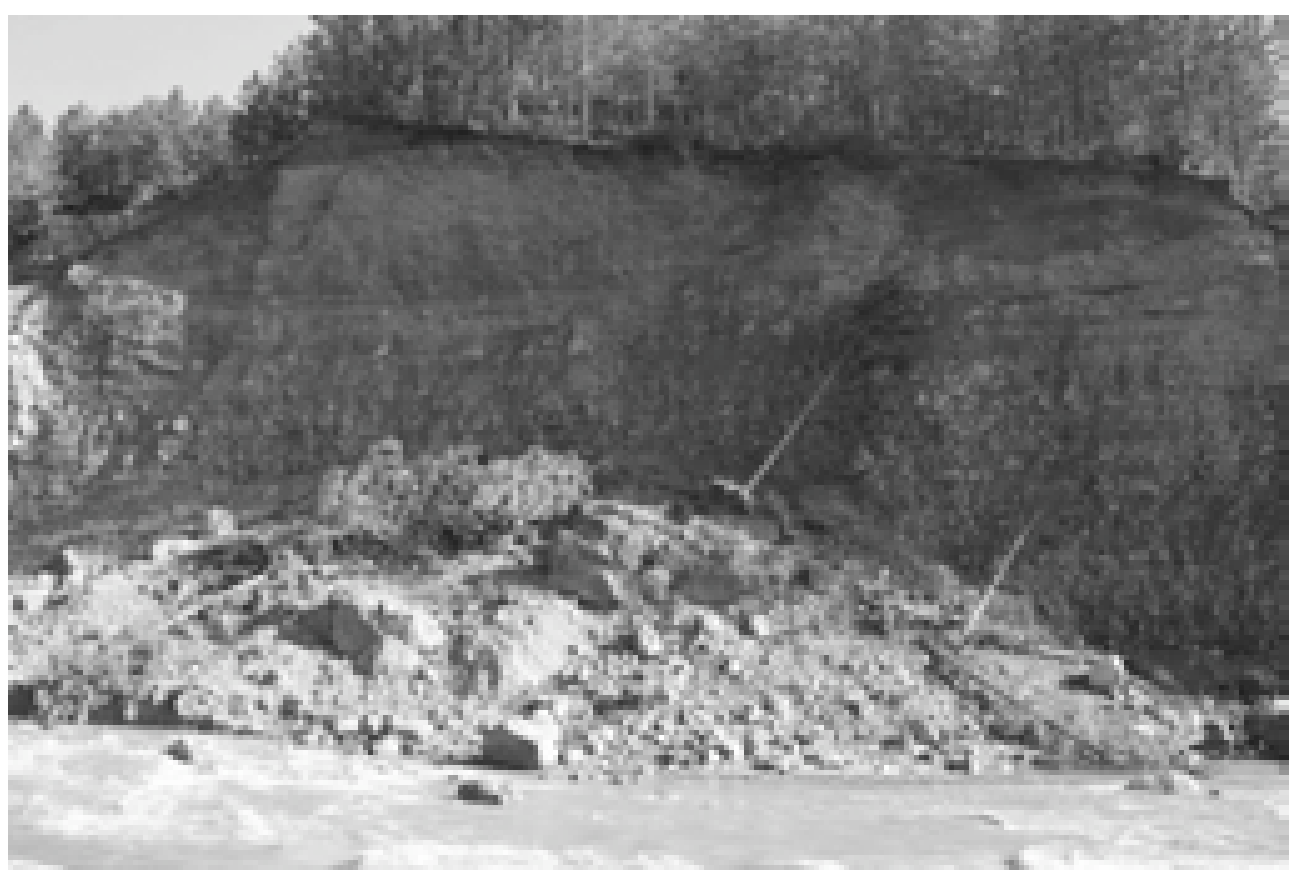

Figura 12. Deslizamiento en la margen izquierda del río Aragón aguas arriba de Castiello. 
El río Aragón derribó igualmente dos pequeñas casas de huerta aguas abajo de Castiello, erosionó el talud de la carretera N-330 (figura 13) y generó daños también en Canfranc, Villanúa y Jaca. En Villanúa destruyó un sector de la escollera del encauzamiento rectilíneo ejecutado hace unos años, iniciando un meandro que amenaza a otra urbanización mal ubicada (figura 14). También en este caso el río ha intentado con la crecida salirse del constreñimiento artificial y recuperar su antiguo cauce. La Confederación va a invertir más de 4 millones de euros en la "reparación de emergencia" de todas estas situaciones: además de la actuación en Castiello, en Villanúa va a restituir y proteger la margen afectada (figura 14) y en Canfranc va a reparar las escolleras de defensa de los tramos urbanos y reconstruirá la margen derecha del río en el tramo colindante con una nave de propiedad comarcal.

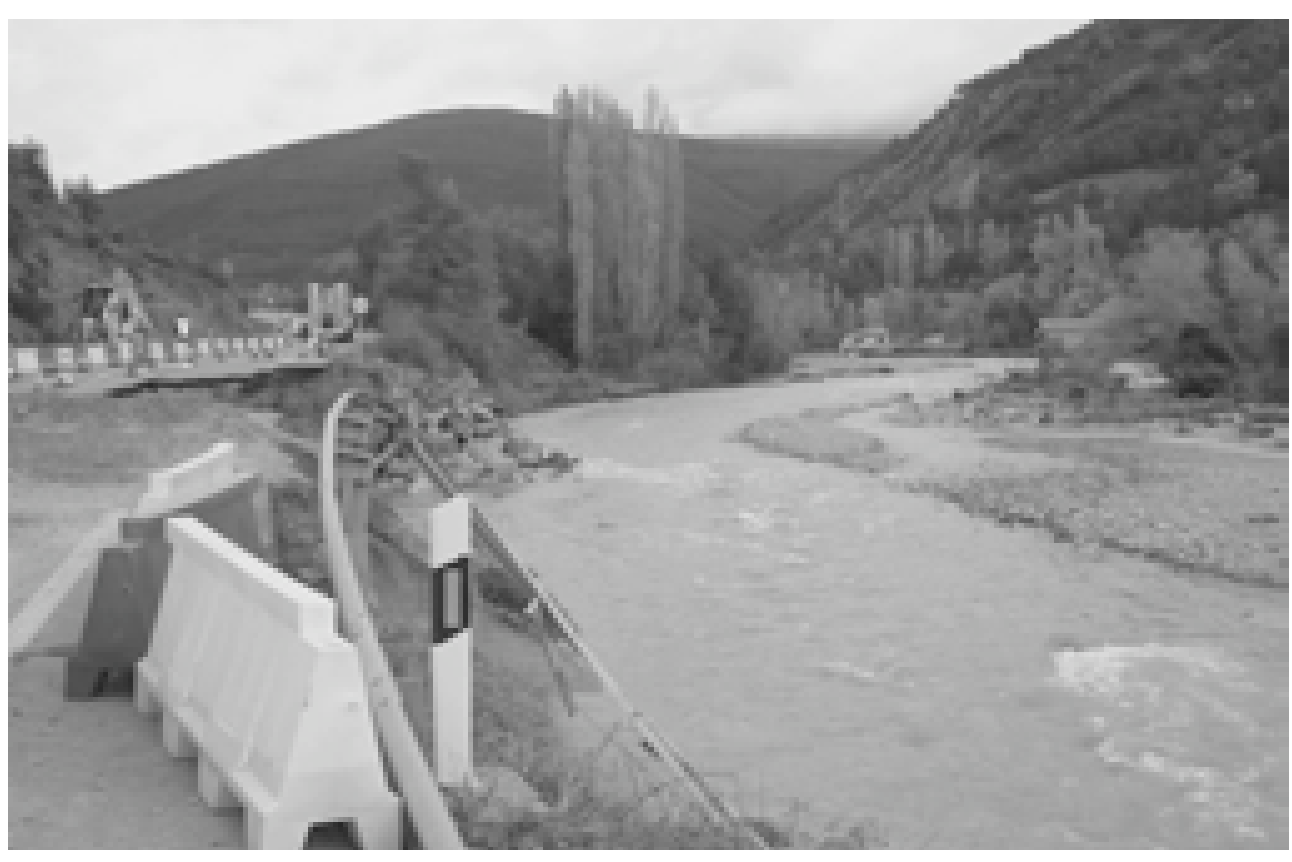

Figura 13. Desperfectos en la carretera N-330 a raíz de la erosión del talud por la crecida del río Aragón aguas abajo de Castiello de Jaca.

La crecida del río Gállego generó escasos daños económicos. Las principales situaciones de riesgo se vivieron en su curso bajo, en el término municipal de Zaragoza. En el barrio rural de Peñaflor fue preciso desalojar la urbanización alegal de Soto Ortiz, afectando también las inundaciones a una perrera y a fincas agrícolas. Una especial preocupación generó el puente de ferrocarril de la papelera de Montañana, ya que la crecida alcanzó su tablero, lo cual provocó un efecto de presa 

J. C. González, D. Granado, A. Ibisate, C. Marcén, D. Mora...

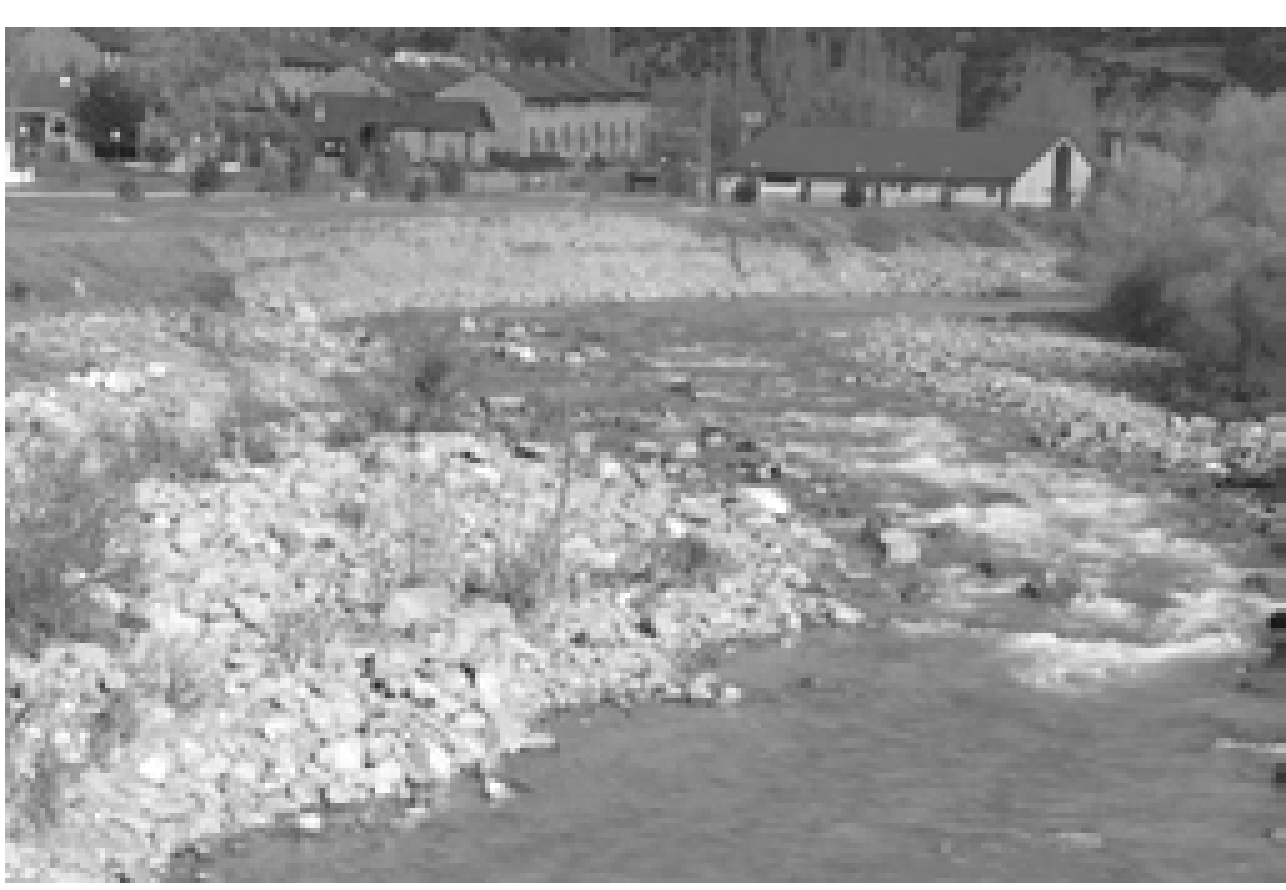

Figura 14. Margen erosionada en Villanúa, afectando directamente a una urbanización construida en el espacio fluvial.

aguas arriba (figura 15). Esta vez no hubo consecuencias, pero se trata claramente de un elemento mal dimensionado, que las crecidas extraordinarias (por encima de 100 años) se verán obligadas a saltar por encima (Ollero y Martín Vide, coords., 2005). Otro punto de riesgo que se saldó finalmente sin daños es la urbanización Villas de Jarandín del barrio zaragozano de Santa Isabel (figura 16). Esta crecida del Gállego ha sido comparable en caudal a la de noviembre de 2003, la cual generó mayores cambios geomorfológicos, como la corta natural de un meandro en las proximidades de Peñaflor. En esta de 2012 tan solo se han renovado apreciablemente (figura 17) todas las barras de sedimentos del curso bajo, que se encontraban muy estabilizadas por la vegetación tras la ausencia de crecidas en los últimos años.

En la cuenca del Cinca la crecida tuvo en general consecuencias menos significativas. Sí es de destacar la crecida del río Ara en Torla, que pasó superando con claridad el nivel del viejo aforo y originó una importante erosión en la margen derecha a la altura de la urbanización Ordesa-Gavarnie. Los trabajos de reconstrucción de esta orilla por la C.H.E. se han integrado en los 4 millones de euros presupuestados (junto con las citadas reparaciones en el río Aragón). En Broto también hubo des- 


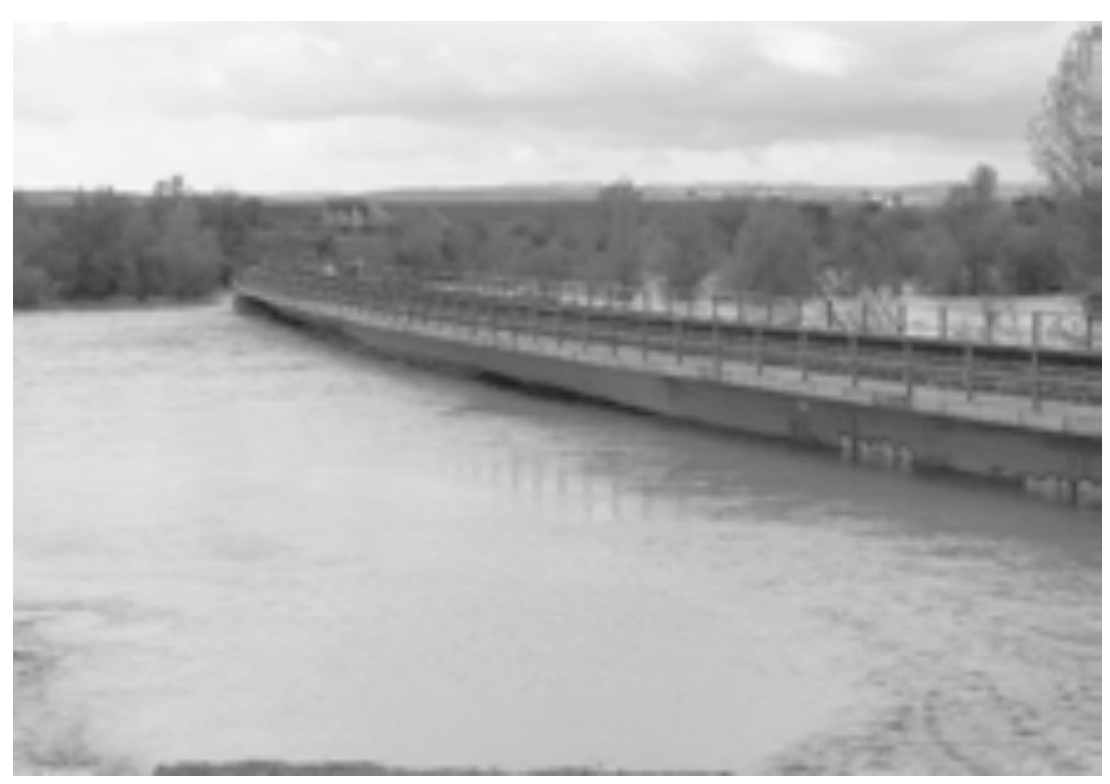

Figura 15. La corriente del río Gállego chocando contra el tablero del puente del ferrocarril de la papelera Montañanesa el 21 de octubre.

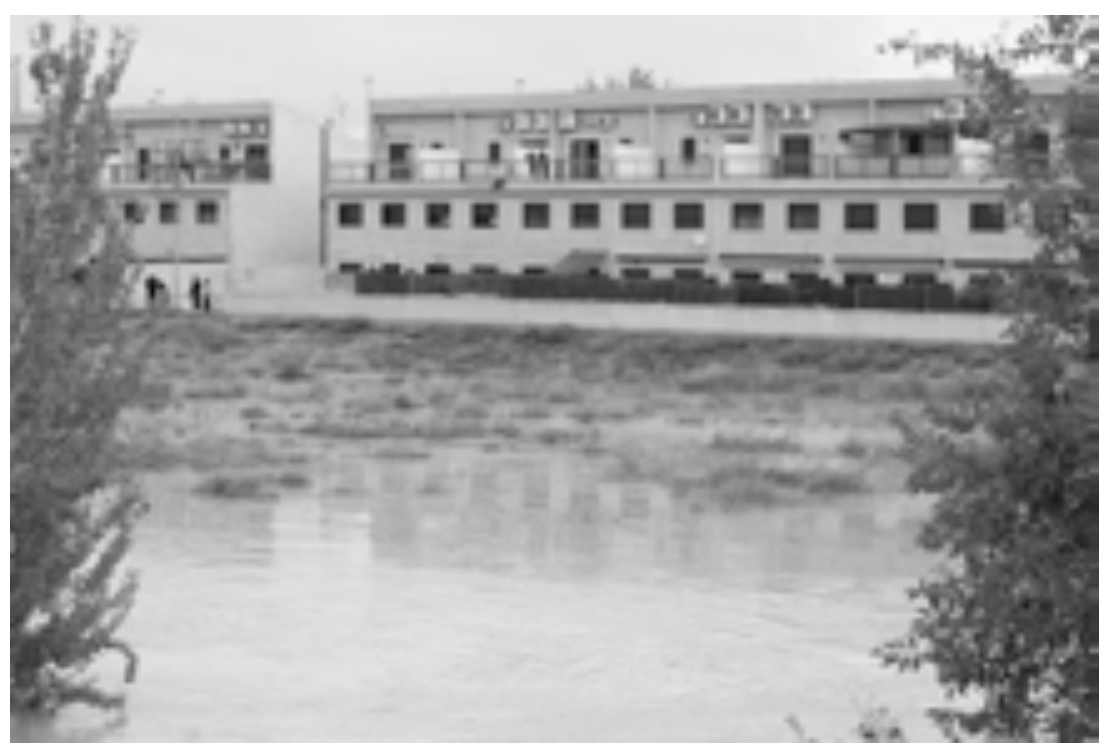

Figura 16. El 21 de octubre a las $12 \mathrm{~h}$. las aguas desbordadas del río Gállego llegaban a escasos metros de la urbanización Villas de Jarandín en Zaragoza. 


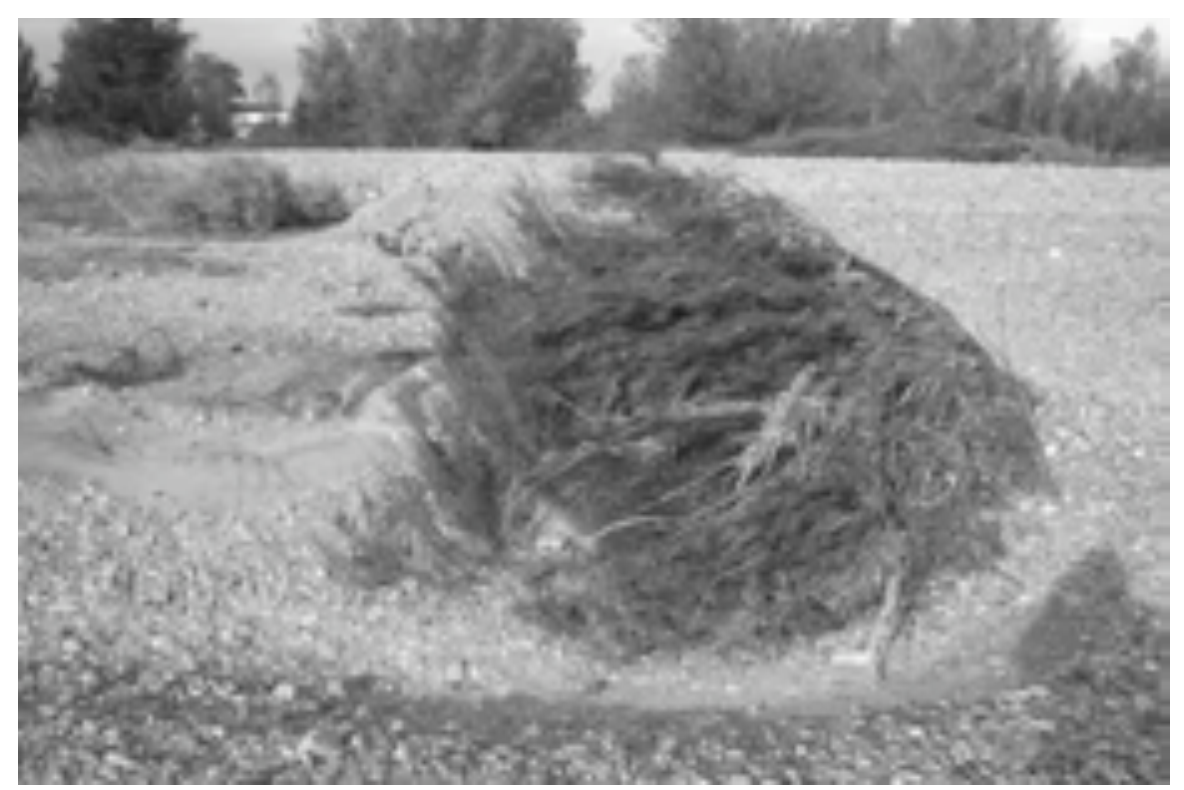

Figura 17. Sedimentos depositados por la crecida enterrando a las antiguas barras colonizadas por la vegetación en el curso final del río Gállego.

bordamientos y en el aforo de Boltaña el Ara marcó un caudal apreciable, pero muy por debajo de la crecida de diciembre de 1997, que fuera incrementada por la rotura de la ataguía de Jánovas (Ibisate et al., 2001). Los ríos Cinca y Ésera produjeron algunos daños en sus cabeceras, pero sus caudales de avenida fueron totalmente retenidos en los embalses. Aguas abajo los ríos Vero, Isábena y Sosa apenas sintieron la crecida, destacando los caudales aportados por el río Alcanadre, que generaron desbordamientos en la huerta fragatina. Más daños causaron el río Flumen (afluente del Alcanadre) y su afluente el río Isuela, que se desbordó en Pompenillo, cuyos habitantes tuvieron que ser desalojados el día 20.

\section{Discusión sobre la gestión del riesgo}

La Directiva Europea de Inundaciones de 2007 declara que hay que respetar las zonas inundables de los ríos, no introduciendo en ellas edificaciones ni actuaciones. También señala que la solución frente a las inundaciones no consiste en aumentar la regulación ni en construir defensas, sino en una ordenación del territorio adecuada y restrictiva que trate de reducir progresivamente los bienes expuestos. En esta línea, el 23 de octubre el Colegio de Geógrafos en Aragón emitió el siguiente comunicado: 
Ante el evento de precipitaciones intensas que ha generado crecidas y desbordamientos en varios cauces de la cuenca del Ebro entre los dias 19 y el 21 de Octubre de 2012, y debido a las declaraciones que se están haciendo a raíz del mismo, el Colegio de Geógrafos en Aragón realiza el siguiente comunicado.

Las crecidas son la respuesta hidrológica que los sistemas fluviales manifiestan ante eventos de lluvias muy intensas, como las acontecidas en el territorio aragonés el pasado fin de semana, muy necesarias para el mantenimiento de la diversidad ecológica, geomorfológica e bidrológica del sistema. No debemos olvidar que los ríos no son sólo los cauces por los que discurre el agua de forma permanente, sino un complejo sistema que comprende la ribera y el llano de inundación, ocupada y explotada por el hombre desde antaño.

La regulación de cuencas fluviales por medio de embalses permite laminar los caudales de crecida aguas abajo de los mismos, minimizando los daños que las avenidas generarian a la población, infraestructuras y en los usos del suelo, tal y como se ha puesto de manifiesto en Yesa o en el sistema Mediano-El Grado, los cuales han retenido los caudales punta del Aragón y de los ríos Ara y Cinca respectivamente. Sin embargo, en el caso del sistema del Gállego, la gestión de éstos no ba permitido reducir la crecida en el tramo bajo de su cuenca, lo que ha demostrado que la mejor de las herramientas a la bora de reducir el riesgo es la ordenación del territorio. Asi mismo, las viviendas derrumbadas en Castiello de Jaca (Huesca) estaban construidas en zona inundable, y la crecida del Aragón nos ha demostrado que el río ocupa sus dominios, aunque sea muy de vez en cuando.

El cálculo de los periodos de retorno de las avenidas registradas debe hacerse con un claro objetivo preventivo, para conocer la probabilidad de ocurrencia de estos fenómenos en el territorio. Hay que considerar que las crecidas acontecidas por muy extraordinarias que sean se pueden volver a repetir, pero eso sí, con distinta probabilidad o frecuencia. En la avenida del río Aragón, por ejemplo, existe una probabilidad entre 500 de que se vuelva a repetir la crecida el próximo año. Debemos así modificar la falsa sensación de seguridad que se genera cuando acontece un evento de tal magnitud.

La educación en los riesgos de inundación es una tarea que debemos seguir desarrollando desde los colegios profesionales, las distintas administraciones y la Universidad, haciendo bincapié en que la mejor forma de reducir los daños por una avenida es en la reducción de los bienes expuestos en zonas inundables y no aludir a la imprevisibilidad de una crecida. Las sociedades actuales somos cada vez menos vulnerables ante eventos extraordinarios, pues boy en dia contamos con herramientas avanzadas para predecir episodios de lluvias intensas y crecidas fluviales, como el Sistema Automático de Información Hidrológica (SAIH) que posee la Confederación Hidrográfica del Ebro. La coor- 
dinación que ha becho el SAIH junto a Protección Civil y emergencias en el pasado episodio, ha permitido no tener que lamentar víctimas mortales y tan sólo cuantiosos daños materiales. La riada del Arba de Riguel en Sádaba ha demostrado que la ubicación del colegio no era la adecuada, y su proximidad al cauce ha hecho que sea una de las edificaciones más afectadas. Desde el Colegio de Geógrafos consideramos que debería reubicarse en un emplazamiento seguro lejos del llano de inundación, reduciendo así la exposición de estos bienes ante futuros eventos de magnitud similar o inferior.

Así pues se debe seguir trabajando en la minimización de los riesgos por inundación desde las distintas administraciones (locales, autonómicas, etc.) intentando hacer una ordenación sostenible de los usos del suelo en los llanos inundables. Las riadas son el riesgo natural más extendido en el territorio aragonés, y lo seguirán siendo en el futuro, tan sólo tenemos que saber convivir con ellas.

El hecho de que estas crecidas se hayan laminado de forma destacable en embalses como Yesa (Aragón), Lanuza-Búbal (Gállego), Mediano-El Grado (Cinca) o Barasona (Ésera), que contaban en esta ocasión con mucha capacidad disponible, ha llevado a algunos sectores a demandar más embalses y a magnificar la utilidad de estas infraestructuras. Esta situación suele generar exceso de confianza y falsa sensación de seguridad, ya que pueden registrarse futuros eventos extremos en los que la capacidad de laminación de los embalses sea nula, por encontrarse llenos. No puede confiarse en una gestión del riesgo asentada en la regulación.

A pesar de ser el organismo competente en la gestión ambiental y de riesgos en la cuenca del Ebro y el encargado de aplicar los principios y las normas de la Directiva 2007/60/CE, la Confederación Hidrográfica del Ebro ha optado por realizar trabajos de emergencia de ejecución inmediata, sin estudio previo y sin planificar, de hecho fueron iniciados solo 5 días después de la crecida, tratando de "reconducir y anular la vía de desagüe que se abrió en un brazo de cauce abandonado" (figura 18), "taponando dicho cauce, que después se rellenará con los sedimentos extraídos del cauce original" (texto procedente de las notas de prensa de la C.H.E.). Para ello, ha obtenido la correspondiente aprobación presupuestaria desde el Ministerio de Agricultura, Alimentación y Medio Ambiente y ha logrado el apoyo del Instituto Aragonés de Gestión Ambiental (INAGA) del Gobierno de Aragón, competente en el procedimiento de evaluación de impacto ambiental, que se ha comprometido a declarar "compatibles" las actuaciones que se realicen en los distintos cauces afectados.

Esta especie de "huída hacia adelante" no es nueva, ni mucho menos, en las administraciones hidráulicas españolas (Olcina, 2008) ni en otros países de nuestro entorno (Vinet, 2010). Como en otros innumerables casos (e.g. Gonzalo et al., 2010), se trata de volver a la situación inicial, sin escuchar el claro mensaje del río, contra- 


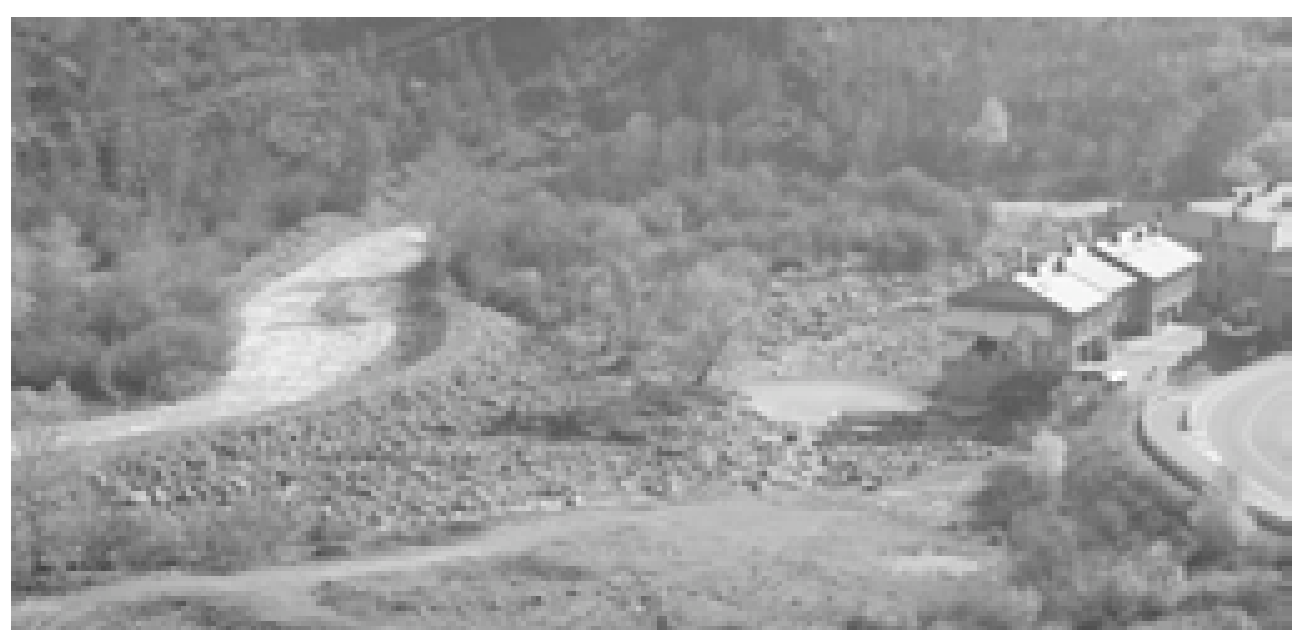

Figura 18. Primera fase de trabajos ya realizada por la C.H.E. (fotografía tomada el 15 de noviembre de 2012) en Castiello de Jaca. A la izquierda se observa el nuevo cauce abierto, más alto y jalonado por una elevación de tierra. A la derecha, al pie de los unifamiliares se conserva el cauce de la crecida, que en la siguiente fase de la actuación será totalmente rellenado de materiales extraídos del río.

rrestando la dinámica fluvial con actuaciones de ingeniería dura sin ningún tipo de cortapisa ni control ambiental. Así, con la excusa de "proteger personas y edificaciones", la C.H.E. reconduce el cauce del Aragón en Castiello de Jaca (figura 14), lo cual es una invitación a que se vuelva a habitar el espacio afectado. Esto supone una importante inversión de dinero público (en este caso concreto 1,5 millones de euros) en una solución irreal que únicamente va a suponer un incremento del riesgo, ya que se va a mantener o aumentar la exposición humana en un espacio en el que el río ha demostrado cuál es su cauce. Con estas obras, además, se va a proporcionar una falsa sensación de seguridad a la población, lo cual incrementará la vulnerabilidad de ésta.

El 26 de octubre el Centro Ibérico de Restauración Fluvial (CIREF), organismo sin ánimo de lucro vinculado al European Centre for River Restoration, emitió la siguiente nota de prensa solicitando la paralización de las obras iniciadas por la C.H.E. en el cauce del río Aragón en Castiello de Jaca y demandando soluciones de ordenación respaldadas por la legislación vigente:

En relación a las labores iniciadas por la Confederación Hidrográfica del Ebro el 25 de octubre de 2012 para "recuperar" el cauce principal del río Aragón en Castiello de Jaca tras la crecida, el Centro Ibérico de Restauración Fluvial manifiesta: 
- Que las actuaciones planteadas e iniciadas (el cierre artificial de un cauce del río y la apertura de otro, protección de márgenes y retirada de sedimentos del cauce), al margen de su dudosa efectividad, suponen el destrozo irreparable del cauce natural del río Aragón y de sus ecosistemas asociados. Pretenden "invalidar definitivamente" un desvio natural de un rí que simplemente ha demostrado cuál es su cauce. Son actuaciones radicalmente contrarias a los principios de las directivas europeas del Agua (2000) y de Gestión de los Riesgos de Inundación (2007), incumpliendo también el Real Decreto 903/2010 de Evaluación y Gestión de Riesgos de Inundación.

- Que dichas actuaciones se han acogido al protocolo de "obras de emergencia" para no pasar ningún tipo de control ni evaluación ambiental.

- Que, por mucho que se actúe con las obras iniciadas, cuando acontezca otra crecida extraordinaria el río volverá a tomar el camino más directo, que es el del cauce situado bajo la urbanización, que seguirá estando gravemente expuesta.

- Que actuar contra el río con defensas no va a solucionar, por tanto, el problema de la seguridad de las personas y bienes, por lo que habría que proceder a ordenar la zona inundable y reducir en ella la exposición humana, como exigen las citadas directivas europeas. Que la urbanización "El Molino" está ubicada dentro del río, en Dominio Público Hidráulico, y por tanto debería ser inhabilitada y expropiada, y no habría que invertir ningún dinero público en su defensa. El Real Decreto 203/2010 recomienda retirar construcciones o instalaciones que supongan grave riesgo, para lo cual su expropiación tendrá la consideración de utilidad pública. El texto refundido de la Ley del Suelo (RDL 2/2008) señala en su articulo 12 que los terrenos con riesgo de inundación deben ser preservados de su transformación urbana y declarados suelo rural.

- Que como ciudadanos no podemos admitir que el Ministerio de Agricultura, Alimentación y Medio Ambiente, a través de la Confederación Hidrográfica del Ebro, en lugar de velar por la seguridad de las personas, trabajar por la calidad ambiental, gestionar con responsabilidad las zonas de riesgo y hacer cumplir los principios de la Directiva Marco del Agua y de la Directiva de Gestión de los Riesgos de Inundación, esté vulnerando muy gravemente los principios fundamentales de dichas directivas, manteniendo una situación de riesgo. Con esa vulneración, que puede ser objeto de sanción desde la Unión Europea, se engaña a la ciudadanía y se da un mal ejemplo de actuación.

- Por todo ello, solicitamos la paralización de las obras y la búsqueda de soluciones de ordenación territorial que sí son seguras, cumplen la ley y pueden ser evaluadas ambientalmente.

Existen, por tanto, posiciones radicalmente encontradas entre científicos y expertos en sistemas fluviales, que reclaman una gestión basada en la reducción de la 
exposición de acuerdo con los principios de la legislación vigente, y los gestores del organismo de cuenca, que mantienen su línea de actuación tradicional basada en luchar frontalmente y con la máxima rapidez contra el funcionamiento fluvial para poder recuperar el mismo uso que se hacía del espacio en riesgo antes del evento. El conflicto está abierto, pero no existe ninguna comunicación entre las dos partes. El poder ejecutivo está en manos de la C.H.E., que sigue adelante con sus trabajos en el río sin ningún tipo de consulta a expertos ni de evaluación ambiental. Ante la falta de diálogo y colaboración, a los científicos solo les queda exigir a la C.H.E. el expediente de los contratos de emergencia y su motivación y elevar una queja a la Comisión Europea (Environment Directorate-General) y a la Comisión de Peticiones del Parlamento Europeo, denunciando el incumplimiento de la Directiva 2007/60/CE.

Hay que destacar los importantes avances normativos y de cartografía preventiva en los últimos años (Díez Herrero et al., 2008), que avalan la posición de los científicos y restauradores fluviales. Destaca la actualización del reglamento del Dominio Público Hidráulico (RD 9/2008 de 11 de enero) con la introducción de criterios geomorfológicos e históricos para definir los cauces naturales y las áreas inundables (Marquínez et al., 2008) y con el reconocimiento de que este D.P.H. cumple funciones ambientales, de protección de los ecosistemas fluviales y de prevención de inundaciones. Es muy destacable lo señalado en el preámbulo: "El enfoque tradicional para abordar este riesgo, consistente en plantear soluciones estructurales (construcción de presas, encauzamientos, motas de defensa, y otros), se ha revelado insuficiente, por lo que resulta necesario profundizar en las medidas de gestión del riesgo como instrumento fundamental para mejorar la protección de la población." Del mismo modo que el caso de Castiello, el ejemplo de la inundación de Sádaba es también evidente, ya que la canalización total del río Riguel no ha evitado en absoluto el desbordamiento. Precisamente la rotura de una parte del muro de protección agravó la inundación y fue responsable de los daños en el colegio.

También hay que destacar la puesta en marcha del Sistema Nacional de Cartografía de Zonas Inundables (S.N.C.Z.I.), definido por el propio Ministerio de Agricultura, Alimentación y Medio Ambiente como un instrumento de apoyo a la gestión del espacio fluvial, la prevención de riesgos, la planificación territorial y la transparencia administrativa. Este S.N.C.Z.I. responde a la exigencia de la Directiva 2007/60/CE de contar con una cartografía de peligrosidad y de riesgo de inundación para el año 2013. Así, lo acontecido en Castiello de Jaca, por ejemplo, ha demostrado que los edificios afectados deberían considerarse incluidos en el Dominio Público Hidráulico. Incluso se sitúan sobre la zona de flujo preferente (Sánchez y Lastra, coords., 2011), lo cual deberá ser actualizado en la cartografía correspondiente del S.N.C.Z.I. De cara al futuro es fundamental que estas cartografías se conviertan en un auténtico sistema de prevención, que estén bien realizadas, que cubran todo el territorio y que sean tenidas en cuenta de forma irrenunciable para cualquier actuación y para determinar estrictamente los usos del territorio. 


\section{Lecciones a aprender}

Todo evento natural de carácter extremo y con daños en el medio socioeconómico constituye un adecuado campo de aprendizaje para profundizar en las relaciones del hombre con el medio y para mejorar de cara al futuro, tratando de no caer en los mismos errores. La educación en el riesgo es fundamental para reducir la vulnerabilidad de la sociedad ante futuros eventos, ya que supone formar y sensibilizar en el respeto hacia las dinámicas naturales, en la precaución, en la adaptación, evitando que las personas formadas caigan en la pérdida de memoria o en la falsa sensación de seguridad. En suma, con la educación en el riesgo la sociedad aumenta su resiliencia.

Los episodios de precipitaciones y las acumulaciones súbitas de agua en los cauces se repetirán, porque la meteorología no entiende de periodos fijos, ni de compromisos sociales. La historia hidrológica nos enseña la posible dimensión de estos eventos, nos asegura que pueden ser en el futuro iguales o superiores a los acontecidos. Conocemos que los ríos de vez en cuando aceleran sus procesos y ocupan todo el espacio que en tiempos les perteneció. Estas "súbitas rebeliones" de los entes vivos que son los ríos buscan recuperar la libertad de sus cauces. En su caminar encuentran obstáculos que nuestro desarrollo socioeconómico, poco prudente en bastantes ocasiones, ha puesto en su trayectoria. Como no han otorgado a sus vecinos compromisos de servidumbre fluyen en su afán de construir territorio y se llevan por delante propiedades y tierras.

Una vez más, nuestros ríos han hablado claro. Quieren recordarnos que es necesario concretar con ellos convivencias duraderas, que siempre se basan en una gestión racional y de sentido común de las zonas inundables. Cuando así se ha hace, las aguas respetan los espacios que no les pertenecen. Nuestra sociedad necesita tener presente estos eventos. Olvidos pasados nos trajeron tragedias múltiples. Las secuelas de la catástrofe emocional y social del camping de Biescas todavía nos afectan, y han pasado 16 años. La ocupación y la privatización de los espacios fluviales suponen firmar una catástrofe futura, aunque la magnitud sea llevadera. Cuesta entender que nuestra sociedad avanzada prefiera, en general, seguir arriesgándose ante los peligros naturales antes que revisar y replantearse ciertos usos del territorio. Utilicemos estos episodios para entender el fluir de los ríos. No podemos detenerlo ni siquiera con el reloj del olvido, que se empeña en marcar con construcciones una parte importante de nuestros cauces fluviales.

\section{Conclusión}

Las abundantes precipitaciones registradas el 19 y 20 de octubre activaron con rapidez y eficiencia todos los procesos hidrogeomorfológicos en vertientes, cárcavas 
y cauces pirenaicos y prepirenaicos aragoneses. Como viene siendo cada vez más frecuente en estos casos, el notable incremento de la exposición humana en las últimas décadas provocó importantes daños, principalmente en áreas de deficiente planificación. De estas consecuencias de las crecidas tenemos que aprender como sociedad. Este episodio extremo ha demostrado que las situaciones de riesgo permanecen o se incrementan en el tiempo y que es urgente la adopción de soluciones de prevención y gestión que vayan más allá de las convencionales medidas de ingeniería fluvial. Es fundamental trabajar en la ordenación de los espacios inundables, en consonancia con los principios de la Directiva 2007/60/CE, de acuerdo con la renovada figura del Dominio Público Hidráulico y con el apoyo de cartografías de zonas inundables permanentemente actualizadas.

\section{Agradecimientos}

A los medios de comunicación aragoneses por el interés mostrado en el tema y el extenso seguimiento realizado, que nos ha permitido contar con información rápida y útil. Al Colegio de Geógrafos en Aragón y al Centro Ibérico de Restauración Fluvial por permitirnos reproducir sus comunicados. A José Luis Escuer (I.E.S. Ramón J. Sender de Fraga) por mostrarnos su trabajo con los estudiantes sobre las crecidas. A Gemma Ruiz, Pilar Cabrero, Alicia Ballarín, Francho Pino, José Bellosta y Francisco Pellicer, que aportaron fotografías de los distintos puntos de riesgo enriqueciendo nuestra base de datos sobre este evento. Y a los colegas del Dpto. de Geografía y Ordenación del Territorio de la Universidad de Zaragoza por animarnos a escribir estas páginas.

\section{Referencias}

Ayala, F.J. (2002) El sofisma de la imprevisibilidad de las inundaciones y la responsabilidad social de los expertos. Un análisis del caso español y sus alternativas. Boletín de la Asociación de Geógrafos Españoles, 33, 79-92.

Díez Herrero, A.; Laín, L. y Llorente, M. (2008) Mapas de peligrosidad por avenidas $e$ inundaciones. Guía metodológica para su elaboración. Madrid, Instituto Geológico y Minero de España.

Domenech, S.; Ollero, A. y Sánchez Fabre, M. (2008) Núcleos de población en riesgo de inundación fluvial en Aragón: diagnóstico y evaluación para la ordenación del territorio. Geographicalia, 54:17-44.

Domenech, S.; Espejo, F.; Ollero, A. y Sánchez Fabre, M. (2011) Peligrosidad por inundaciones en una cuenca no aforada: el río Sosa en Monzón (Huesca) y el evento de agosto de 2006. Geographicalia, 59-60, $95-$ 108.

Espejo, F. (2008) Hacia una tipología de inundaciones en la cuenca del Ebro en función de sus causas atmosféricas. Geograpbicalia, 53: 73-100.

Estrela, M.J.; Millán, M.; Peñarrocha, D. y Pastor, F. (2002) De la gota fría al frente de 
retroceso. Alzira, Centro Francisco Tomás y Valiente, UNED.

García Ruiz, J.M.; White, S.; Martí, C.; Valero, B.; Errea, M.P. y Gómez Villar, A. (1996) La catástrofe del barranco de Arás (Biescas, Pirineo Aragonés) y su contexto espaciotemporal. Zaragoza, Instituto Pirenaico de Ecología.

García Ruiz, J.M.; Beguería, S. y Lorente, A. (2000) Eventos hidrológicos de baja frecuencia en el Pirineo central español y sus efectos geomorfológicos. Serie Geográfica, 9, 163-176.

García Ruiz, J.M.; Martí, C.; Lorente, A. y Beguería, S. (2002) Geomorphological consequences of frequent and infrequent rainfall and hydrological events in Pyrenees mountains in Spain. Mitigation and Adaptation Strategies for Global Change, 7, 303-320.

Gonzalo, L.E.; Ollero, A.; Ibisate, A. y Ballarín, D. (2010) Impacto geomorfológico de actuaciones en cauces fluviales de La Rioja. Zubia, 28: 7-30.

Ibisate, A.; Ollero, A. y Díaz, E. (2001) Las crecidas del río Ara y el evento extraordinario de diciembre de 1997. El río Ara es de todos, 65-78, Zaragoza, Asociación Río Ara.
Marquínez, J.; Díez Herrero, A.; Fernández, E.; Lastra, J. y Llorente, M. (2008) Aspectos geomorfológicos en la modificación del Reglamento del Dominio Público Hidráulico y el Sistema Nacional de Cartografía de Zonas Inundables. Trabajos de Geomorfología en España 2006-2008, $X$ Reunión Nacional de Geomorfología, 377-380, Cádiz.

Olcina, J. (2008) Cambios en la consideración territorial, conceptual y de método de los riesgos naturales. Scripta Nova. Revista Electrónica de Geografía y Ciencias Sociales, XII, 270(24).

http://www.ub.es/geocrit/sn/sn-270/sn270-24.htm.

Ollero, A. y Martín Vide, J.P. (coords., 2005) Estudio bidrológico, geomorfológico, bidráulico y ecológico del bajo Gállego en el término municipal de Zaragoza para su gestión como espacio fluvial. Ayuntamiento de Zaragoza.

Sánchez, F.J. y Lastra, J. (coords, 2011) Guía metodológica para el desarrollo del Sistema Nacional de Cartografia de Zonas Inundables. Madrid, Ministerio de Medio Ambiente y Medio Rural y Marino.

Vinet, F. (2010) Le risque inondation. Diagnostic et gestion. Paris, Tec \& Doc Lavoisier. 